\title{
nNOS-Expressing Neurons in the Ventral Tegmental Area and Substantia Nigra Pars Compacta
}

\author{
(DEleanor J. Paul, ${ }^{1,2}$ Eliza Kalk, ${ }^{1,2}$ Kyoko Tossell,, ${ }^{1,2,3}$ Elaine E. Irvine, ${ }^{1,2}$ CNicholas P. Franks, ${ }^{3}$ \\ ㄴ. William Wisden, ${ }^{3}$ - Dominic J. Withers, ${ }^{1,2}$ James Leiper, ${ }^{1,2}$ and ${ }^{-}$Mark A. Ungless ${ }^{1,2}$
}

https://doi.org/10.1523/ENEURO.0381-18.2018

${ }^{1}$ MRC London Institute of Medical Sciences (LMS), London W12 ONN, United Kingdom, ${ }^{2}$ Institute of Clinical Sciences (ICS), Faculty of Medicine, Imperial College London, London W12 ONN, United Kingdom, and ${ }^{3}$ Department of Life Sciences, Imperial College London, South Kensington, London SW7 2AZ, United Kingdom

\begin{abstract}
GABA neurons in the VTA and SNc play key roles in reward and aversion through their local inhibitory control of dopamine neuron activity and through long-range projections to several target regions including the nucleus accumbens. It is not clear whether some of these GABA neurons are dedicated local interneurons or if they all collateralize and send projections externally as well as making local synaptic connections. Testing between these possibilities has been challenging in the absence of interneuron-specific molecular markers. We hypothesized that one potential candidate might be neuronal nitric oxide synthase (nNOS), a common interneuronal marker in other brain regions. To test this, we used a combination of immunolabelling (including antibodies for nNOS that we validated in tissue from nNOS-deficient mice) and cell type-specific virus-based anterograde tracing in mice. We found that nNOS-expressing neurons, in the parabrachial pigmented (PBP) part of the VTA and the SNc were GABAergic and did not make detectable projections, suggesting they may be interneurons. In contrast, nNOS-expressing neurons in the rostral linear nucleus (RLi) were mostly glutamatergic and projected to a number of regions, including the lateral hypothalamus (LH), the ventral pallidum (VP), and the median raphe $(\mathrm{MnR})$ nucleus. Taken together, these findings indicate that nNOS is expressed by neurochemically- and anatomically-distinct neuronal sub-groups in a sub-region-specific manner in the VTA and SNc.
\end{abstract}

Key words: GABA; glutamate; nNOS; SNc; VTA

\section{Significance Statement}

GABA neurons in the VTA and SNc play important roles in reward and aversion through their local control of dopamine neuron activity and long-range projections to regions such as the nucleus accumbens. It is not clear whether some of these neurons are dedicated interneurons, or if they all project externally and synapse locally. We find that neuronal nitric oxide synthase (nNOS) is expressed by some GABAergic neurons that do not make detectable projections, suggesting that they may be interneurons. In addition, nNOS is expressed by a subgroup of glutamatergic neurons that project to regions including the ventral pallidum (VP) and median raphe (MnR) nucleus. Our study paves the way for future investigation of the function of these molecularly-defined populations.

\section{Introduction}

Around one third of neurons in the VTA and SNc are GABAergic (Olson and Nestler, 2007; Nair-Roberts et al.,

Received October 1, 2018; accepted October 2, 2018; First published October 29, 2018.

The authors declare no competing financial interests.

Author contributions: E.J.P., E.K., K.T., E.E.I., N.P.F., W.W., D.J.W., J.L., and M.A.U. designed research; E.J.P., E.K., K.T., and E.E.I. performed research;
2008). These neurons make local, inhibitory synaptic connections with dopamine neurons and their activation can drive conditioned place aversion and reduce food con-

N.P.F. and W.W. contributed unpublished reagents/analytic tools; E.J.P. and E.K. analyzed data; E.J.P. and M.A.U. wrote the paper.

This work was supported by United Kingdom Medical Research Council (MRC) Grants MC-A654-5QB70 (to M.A.U.), MC-A654-5QB60 (to J.L.), and MC-A654-5QB40 (to D.J.W.) and by Wellcome Trust Grants 107839/Z/15/Z (to 
sumption (Omelchenko and Sesack, 2009; Tan et al., 2012; van Zessen et al., 2012). In addition, they send long-range axonal projections to several target regions, including the nucleus accumbens where they can regulate associative learning (Brown et al., 2012; Taylor et al., 2014). It is not clear whether a subset of these GABA neurons are dedicated local interneurons or if they all collateralize and send projections externally as well as making local synaptic connections. Testing between these possibilities has been challenging in the absence of interneuron-specific molecular markers. Indeed, of the cardinal interneuron markers used to identify and selectively target sub-populations of interneurons in other regions of the brain, most are either not expressed in either the VTA or SNc, or are also expressed by sub-groups of dopamine neurons (e.g., somatostatin, cholecystokinin, vasoactive intestinal peptide, neuropeptide $Y$, parvalbumin, and calretinin; Hökfelt et al., 1980; Seroogy et al., 1988, 1989; Rogers, 1992; Isaacs and Jacobowitz, 1994; Liang et al., 1996; Gonzalez-Hernandez and Rodriguez, 2000; Klink et al., 2001; Lein et al., 2007; Olson and Nestler, 2007; Dougalis et al., 2012; Merrill et al., 2015). One potential candidate, however, is neuronal nitric oxide synthase (nNOS). nNOS is a member of the NOS family of enzymes that catalyze the synthesis of NO from L-arginine (Knowles et al., 1989; Garthwaite, 1991). In the nervous system NO acts as a gaseous transmitter that can move rapidly across plasma membranes in anterograde and retrograde directions (Garthwaite and Boulton, 1995; Wang and Marsden, 1995). In several brain regions nNOS is selectively expressed by specific types of GABAergic interneurons (Klausberger and Somogyi, 2008; Tepper et al., 2010). Although several reports indicate that nNOS is expressed sparsely in the VTA and/or the SNc, there are discrepancies regarding the extent of its expression, which sub-regions it is expressed in, and the degree of colocalization with tyrosine hydroxylase $(\mathrm{TH}$; the rate limiting enzyme in dopamine synthesis that is most commonly used to identify dopamine neurons; Vincent and Kimura, 1992; Rodrigo et al., 1994; GonzalezHernandez and Rodriguez, 2000; Backes and Hemby, 2003; Klejbor et al., 2004; Gotti et al., 2005; CavalcantiKwiatkoski et al., 2010; Mitkovski et al., 2012). We hypothesized that some of these discrepant findings may have arisen because of non-specific immunolabelling. To address this directly, we tested three different nNOS antibodies for reliable immunolabelling in the VTA and SNc, using tissue from nNOS-deficient mice as a control. This allowed us to establish that only one of these antibodies exhibited reliable immunolabelling in the VTA and SNc.

\footnotetext{
N.P.F.) and 107841/Z/15/Z (to W.W.).

Correspondence should be addressed to Mark A. Ungless, Institute of Clinical Sciences (ICS), Faculty of Medicine, Imperial College London, Du Cane Road, London W12 0NN, United Kingdom, E-mail: mark.ungless@imperial.ac.uk.

https://doi.org/10.1523/ENEURO.0381-18.2018

Copyright (C) 2018 Paul et al.

This is an open-access article distributed under the terms of the Creative Commons Attribution 4.0 International license, which permits unrestricted use, distribution and reproduction in any medium provided that the original work is properly attributed.
}

Using this antibody, combined with cell type-specific viral-based anterograde axonal tracing, we found that nNOS is expressed by several distinct sub-groups of neurons in the VTA and SNc, including GABAergic neurons that do not appear to make projections and may therefore be interneurons, and glutamatergic projection neurons.

\section{Materials and Methods}

\section{Animal maintenance and breeding}

C57BI/6NCrl (RRID: IMSR_CRL:27; WT) mice were purchased from Charles River. nNOS-deficient (RRID: IMSR_JAX:002986), NOS1Cre (RRID: IMSR_JAX:017526), VGATCre (vesicular GABA transporter; RRID: IMSR_JAX: 016962), and RiboTag (RRID: IMSR_JAX:011029) mice were purchased from The Jackson Laboratory. Mice heterozygous for VGATCre (VGATCre -/+) were crossed with mice homozygous for RPL22 ${ }^{\mathrm{HA}}$ (RiboTag $+/+$ ) producing VGATCre -/+ RiboTag -/+ offspring (VGATCre: RiboTag). NOS1Cre mice were heterozygous. All breeding and experimental procedures were conducted in accordance with the Animals (Scientific Procedures) Act of 1986 (United Kingdom) and approved by Imperial College London's Animal Welfare and Ethical Review Body. All mice were maintained in social groups of two to four, where possible, with appropriate environmental enrichment (e.g., bedding and tunnels). They were kept in rooms at a constant temperature and maintained on a 12/12 $\mathrm{h}$ light/dark cycle. They were fed on standard rodent chow and water ad libitum.

\section{Tissue fixation and preparation}

C57BI/6NCrl, nNOS-deficient, VGATCre:RiboTag, or NOS1Cre mice were anaesthetized under isoflurane (4\%) and given a lethal intraperitoneal injection of pentobarbital $(100 \mathrm{mg} / \mathrm{ml}$; Euthatal). They were transcardially perfused with $50 \mathrm{ml}$ of ice-cold PBS followed by $50-100 \mathrm{ml}$ of $4 \%$ paraformaldehyde (PFA; Sigma Aldrich) in PBS. When fixed, the brains were removed and placed in $10 \mathrm{ml}$ of $4 \%$ PFA for $1 \mathrm{~h}$ post-fixation at room temperature. After three washes in PBS, brains were placed in $30 \%$ sucrose (Sigma Aldrich) dissolved in PBS for cryo-protection, and kept at $4^{\circ} \mathrm{C}$ for $24-48 \mathrm{~h}$. Subsequently, all brains were embedded in optimal cutting temperature (OCT) medium and snap frozen in isopentane (2-methlybutane) at $-55^{\circ} \mathrm{C}$. All tissue was then stored at $-80^{\circ} \mathrm{C}$ until sectioning.

\section{Immunocytochemistry}

All immunolabelling was conducted on tissue from mice aged 8-12 weeks old. Brains were sectioned using a Leica CM1800 cryostat (Leica Microsystems). Coronal sections $(30 \mu \mathrm{m})$ were taken from the midbrain, or from the whole brain in the case of Nos1Cre mice. Free floating sections were washed in PBS for 10 min at room temperature. Following this, they were blocked in $6 \%$ normal donkey serum (NDS) in $0.2 \%$ Triton X-100 in PBS (PBSTx) for $60 \mathrm{~min}$ at room temperature. Primary antibodies (Table 1) were diluted in $2 \%$ donkey serum in PBSTx, and 
Table 1. Primary antibodies

\begin{tabular}{|c|c|c|c|}
\hline Antibody & Host species & Supplier (catalog number; RRID) & Concentration \\
\hline Anti-TH & Chicken & Abcam (ab76442; AB_1524535) & $1: 1000$ \\
\hline Anti-nNOS & Rabbit & Cell Signalling (4234; AB_10694499) & $1: 500$ \\
\hline Anti-HA & Mouse & Sigma Aldrich (H3663; AB_262051) & $1: 1000$ \\
\hline Anti-HA & Rabbit & Abcam (ab9110; AB_307019) & $1: 500$ \\
\hline Anti-5HT & Rabbit & ImmunoStar (20080; AB_572263) & $1: 2000$ \\
\hline Anti-substance P & Guinea pig & Abcam (ab10353; AB_297089) & $1: 500$ \\
\hline Anti-AADC & Rabbit & Millipore (AB1569; RRID:AB_90789) & $1: 500$ \\
\hline Anti-DAT & Rat & Millipore (MAB369; RRID:AB_2190413) & $1: 500$ \\
\hline
\end{tabular}

sections were incubated in the primary antibody solutions overnight at $4^{\circ} \mathrm{C}$. Sections were washed $(3 \times 10 \mathrm{~min})$ in PBS at room temperature. Secondary antibodies (Table 2) were diluted in $2 \%$ donkey serum $0.2 \%$ PBSTx. Sections were incubated in secondary antibody solution for a minimum of $1.5 \mathrm{~h}$ at room temperature. They were then washed $(3 \times 10 \mathrm{~min})$ in PBS. Stained sections were mounted onto glass microscope slides and when dry were cover-slipped using VectaShield mounting medium (Vector Laboratories). SNc and VTA regions were determined using tyrosine hydroxylase (TH) expression. Region outlines were traced from Franklin and Paxinos (2008).

\section{Microscopy}

Confocal images were acquired using a Leica SP5 confocal microscope with the pinhole set at 1 Airy unit. All images were processed with Fiji software. Images of cell bodies were acquired with z-stacks of $1 \mu \mathrm{m}$. To determine colocalization, channels were viewed both individually and in composite. Colocalization was determined if the cell body was visible in multiple channels through its entire thickness (multiple z-planes). Representative examples of stacked images are shown. Images of axon terminals in nNOS + neuron target areas were acquired with z-stacks of $0.5 \mu \mathrm{m}$. Ten z-planes were stacked and brightness, and contrast was adjusted equally across all axonal projection images for comparison. Images of synaptic terminals were acquired with z-stacks of $0.25 \mu \mathrm{m}$. ChR2-mCherry + synaptic boutons were located in single $z$-planes, which were extracted from the stack to determine colocalization with VGAT or VGluT2.

\section{Stereotaxic injections of adeno-associated virus (AAV)}

The 1-Ef1a-DIO-ChR2-mCherry construct (gifted by the Deisseroth Lab) was commercially packaged in AAV serotype 2/1 vector consisting of the AAV2 ITR genomes and the AAV1 serotype capsid gene (Vector Biolab, Philadelphia). The virus was diluted in sterile PBS and $5 \%$ glycerol ( $\mathrm{pH} 7.2)$ to a concentration of $2.7 \times 10^{13} \mathrm{GC} / \mathrm{ml}$. All viral tracing experiments were conducted on adult (11-13 weeks) NOS1Cre $(-/+)$ mice. Mice were briefly anaesthetized in an induction chamber with isoflurane (4\%) and placed in a stereotaxic frame (David Kopf Instruments) with continued isoflurane administration (2\%). The eyes were protected with Lacri-lube, the scalp was shaved, and the skin disinfected with chlorheximide. All mice received a subcutaneous injection of carprofen (Rimadyl; $5 \mathrm{mg} / \mathrm{kg}$ ) for post-operative anesthesia. An incision $(<1 \mathrm{~cm})$ was made along the midline, and bupivacaine $(2.5 \mathrm{mg} / \mathrm{ml})$ was delivered directly to the incision site for local analgesia. A small hole was drilled in the scalp based on coordinates from bregma. Using a 33-gauge metal needle and a Hamilton syringe the virus solution (0.1 $\mu l)$ was injected unilaterally at a flow rate of $0.3 \mu \mathrm{l} / \mathrm{min}$. We systematically varied the injection coordinates [anteriorposterior (AP) -3.0-3.4 mm, medial-lateral (ML) 0.4-0.9 $\mathrm{mm}$, dorsal-ventral (DV) 4.3-4.8 mm] to obtain labeling of different sub-regions. The flow rate was controlled by a programmable pump (Elite Nanomite Infusion/Withdrawal Programmable Pump 11, 704507, Harvard Apparatus). After injection, the needle was left in place for $5 \mathrm{~min}$ to allow for the spread of the virus. The incision was then sutured using nylon monofilament, non-absorbable su-

Table 2. Secondary antibodies

\begin{tabular}{lllll}
\hline Antibody & Conjugation & Host species & Supplier (catalog number; RRID) & Concentration \\
Anti-chicken & Alexa Fluor 488 & Goat & Thermo Fisher Scientific (A-11039; AB_2534096) \\
Anti-chicken & Cy3 & Donkey & Jackson ImmunoResearch Labs (703-165-155; AB_2340363) & $1: 1000$ \\
Anti-mouse & Cy3 & Donkey & Jackson ImmunoResearch Labs (715-165-150: AB_2340813) & $1: 1000$ \\
Anti-mouse & Cy5 & Donkey & Jackson ImmunoResearch Labs (715-175-151; AB_2340820) & $1: 1000$ \\
Anti-rabbit & Alexa Fluor 633 & Goat & Thermo Fisher Scientific (A21070; AB_2535731) \\
Anti-rabbit & Cy3 & Donkey & Jackson ImmunoResearch Labs (711-165-152; AB_2307443) & $1: 1000$ \\
Anti-goat & Alexa Fluor 488 & Donkey & Thermo Fisher Scientific (A11055; AB_2534102) \\
Anti-guinea pig & Alexa Fluor 488 & Goat & Thermo Fisher Scientific (A11073: AB_2534117) \\
Anti-rat & Alexa Fluor 488 & Goat & Thermo Fisher Scientific (A-11006; RRID:AB_2534074)
\end{tabular}


A

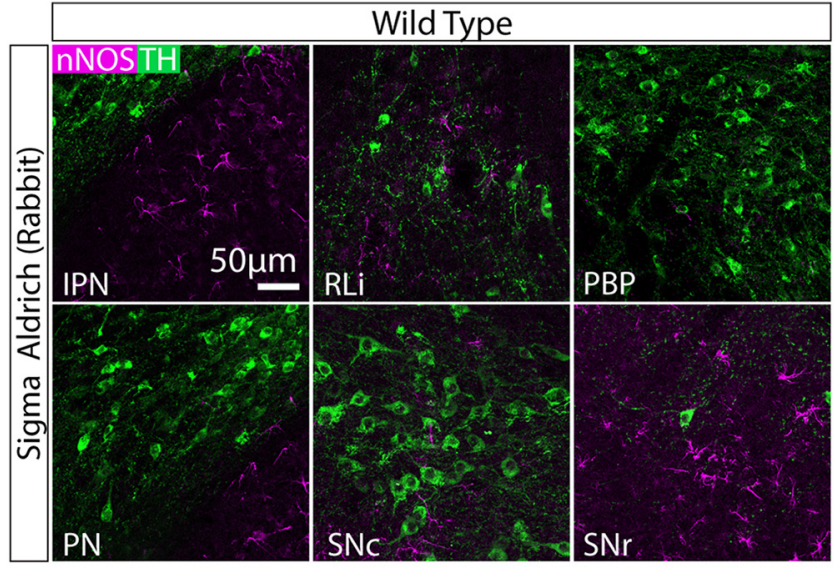

B

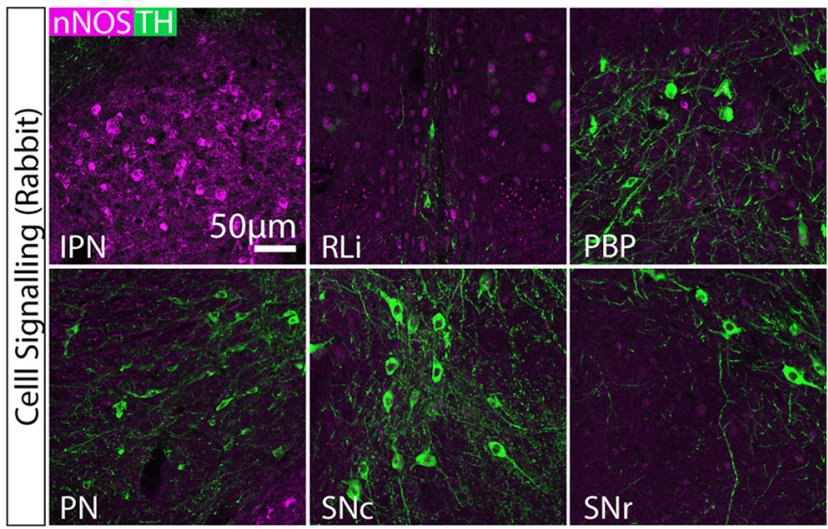

C

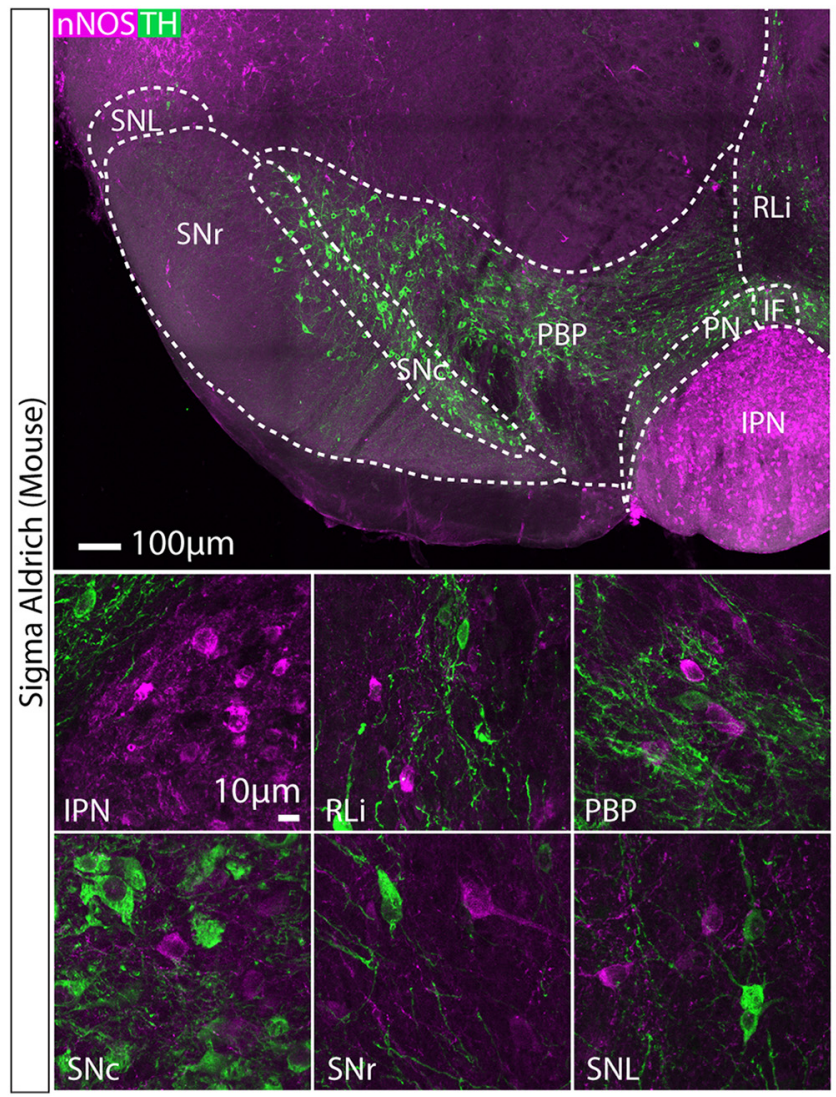

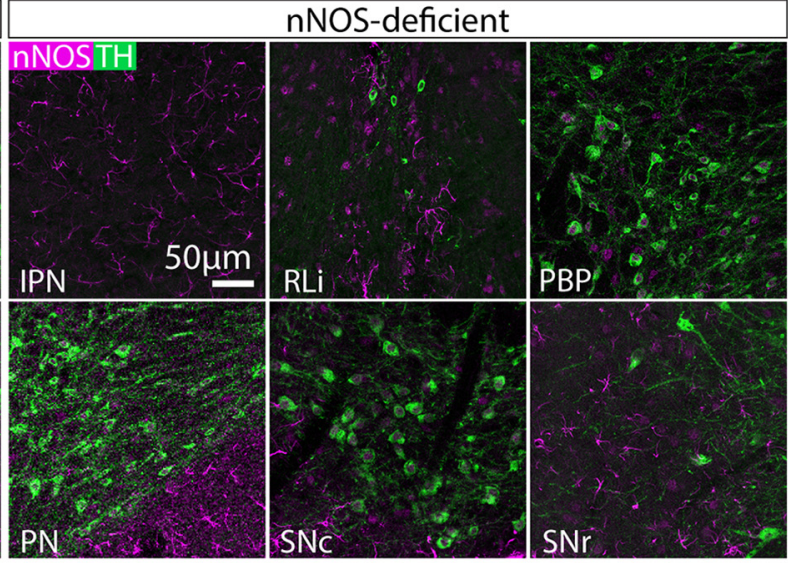

nNOSTH

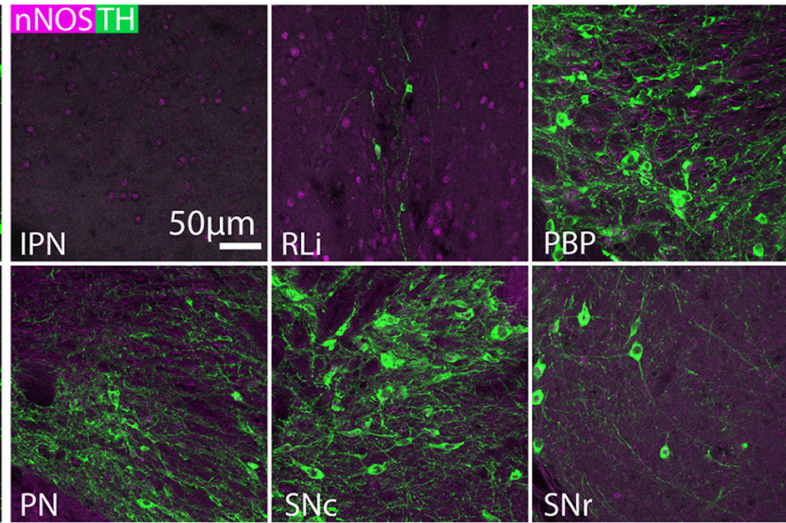

nNOSTH

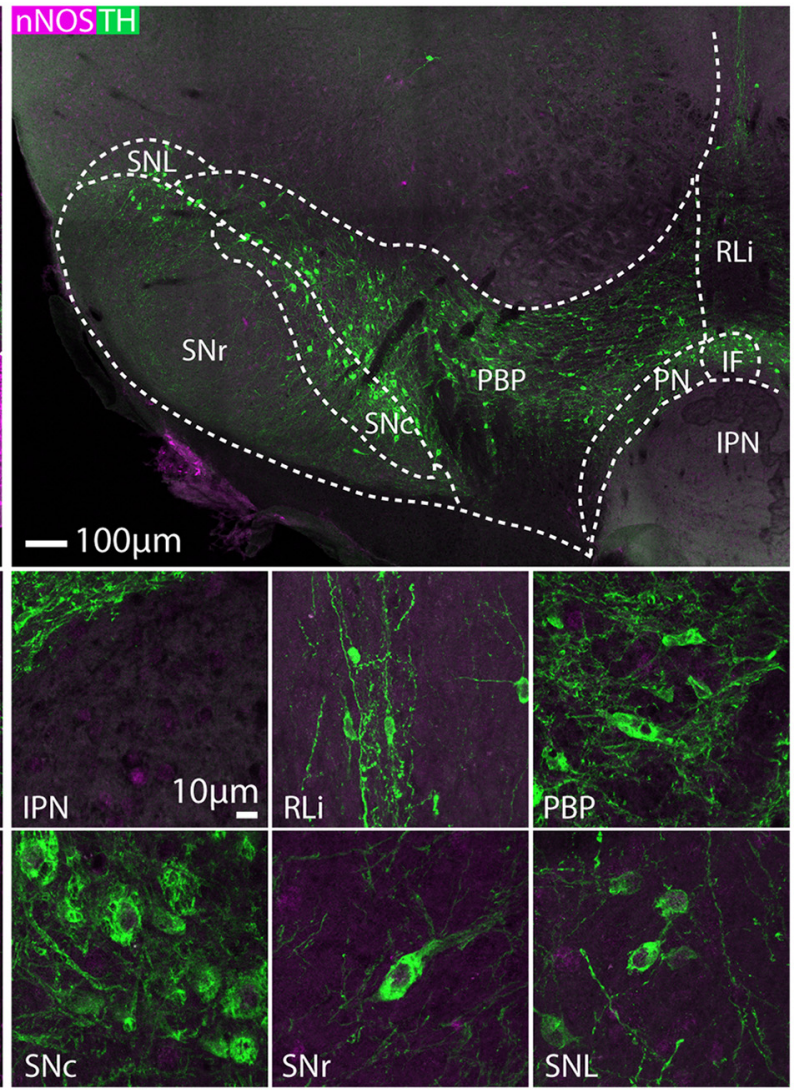

Figure 1. Comparison of three different anti-nNOS antibodies (for details, see Tables 1, 2) in the midbrain of wild-type and nNOS-deficient mice. Representative images of double immunolabelling for nNOS (magenta) and TH (green). A, Anti-nNOS (Sigma 
continued

Aldrich; N7155; AB 260795) exhibited non-specific immunolabelling that was also seen in tissue from nNOS-deficient mice. $\boldsymbol{B}$, Anti-nNOS (Cell Signaling; 4234; AB_10694499) also exhibited somewhat non-specific immunolabelling, that was only partially absent in tissue from nNOS-deficient mice. C . Anti-nNOS (Sigma Aldrich; N2280; AB_260754) exhibited specific immunolabelling that was absent in tissue from nNOS-deficient mice. In wild-type tissue, nNOS + cells were observed in the IPN, RLi, PBP, SNc, SNr, and substantia nigra pars lateralis (SNL). There was no colocalization between nNOS and TH.

tures (size 2-0, 95060-062, VWR). Mice were allowed to recover in a heated chamber $\left(30^{\circ} \mathrm{C}\right)$ before being placed back into their home cage with littermates. All mice were monitored for five days after surgery, during which time they had access to carprofen (Rimadyl; $50 \mathrm{mg} / \mathrm{ml}$ ) in their drinking water. Two weeks after surgery, the mice underwent transcardial perfusion, as described above, and tissue processed for microscopy.pAAV-hSyn-DIO-mCherry was a gift from Bryan Roth (Addgene plasmid \#50459). The pAAV transgene plasmid was packaged into a mixture of serotypes AAV1 and AAV2 (1:1) as previously described (Klugmann et al., 2005; Yu et al., 2015). All other details were the same as for the DIO-ChR2-mCherry experiments, except that the AAV was injected using a Nanoject III Programmable Nanolitre Injector (Drummond Scientific; 3-000-207) with a mineral oil filled glass micropipette. A volume or either 10 or $30 \mathrm{nl}$ was injected at a rate of $3 \mathrm{nl} / \mathrm{s}$, and then the needle was left in position for $10 \mathrm{~min}$ to allow for spread of the virus.

\section{Experimental design and statistics}

Wild type versus nNOS deficient

To compare nNOS antibody staining in wild-type and nNOS-deficient mice, the experimenter was blind to the strain of the mouse from the stage of immunolabelling until after image analysis. Mice for each experimental group were stained in parallel to control for differences between staining experiments. All images in this section were obtained with matched confocal settings. Each antinNOS antibody was tested in a total of three male WT and three male nNOS-deficient mice. The concentration of nNOS antibody was optimized through staining and imaging at three concentrations $(1: 250,1: 500,1: 1000)$. Images from the optimum concentration of 1:500 are shown.

\section{Quantification of nNOS-expressing neurons}

For the quantification of nNOS-expressing neurons triple immunolabelling for $\mathrm{nNOS}, \mathrm{HA}$, and $\mathrm{TH}$ was conducted in three male VGATCre:RiboTag mice. To obtain estimates of the numbers of nNOS neurons, and their neurotransmitter phenotype, every fourth midbrain section was selected for staining and imaging. Tile-scans were taken of the entire VTA and SNc visible on the right-hand side of the brain section. Merged tile-scan images were processed using Fiji (ImageJ) and VTA and SNc sub-region anatomy was defined based on TH expression. $\mathrm{HA}+$ cells, nNOS + cells and HA+/nNOS + were counted in each sub-region using the ImageJ cell counter plugin.

nNOS neuron circuit tracing and ChR2-mCherry colocalization

A total of 18 (eight males and 10 females) virus injected NOS1Cre mice exhibited ChR2-mCherry expression in the VTA and SNc. Eight of these mice also exhibited
ChR2-mCherry expression in the supramamillary nucleus and were therefore excluded from further investigation. The remaining 10 mice were used to examine the axonal projections of nNOS + neurons and further immunolabelling experiments. To investigate the colocalization of ChR2-mCherry, nNOS and TH, images of sub-regions were processed using Fiji (ImageJ). All ChR2-mCherry+ cells were counted in each image using the ImageJ cell counter plugin.

\section{Statistics}

Data are presented as mean \pm SEM. Statistical comparisons were made using one-way ANOVA and Newman-Keuls post hoc tests, where appropriate (Prism, GraphPad Software Inc).

\section{Results}

\section{Comparison of three different anti-nNOS antibodies in the midbrain of wild-type and nNOS-deficient mice}

We first wanted to identify a reliable nNOS antibody for use in the VTA and SNc. We tested three different commercially available antibodies (Tables 1,2$)$. We initially tested each antibody at three different concentrations $(1: 1000,1: 500,1: 250)$. For all three antibodies the 1:500 concentration appeared optimal in terms of reliably exhibiting immunolabelling in the interpeduncular nucleus (IPN) and in regions of the VTA and SNc in wild-type mice (Fig. 1). to thoroughly verify their specificity, each antibody $(1: 500)$ was used on midbrain sections from both wildtype mice $(n=3)$ and nNOS-deficient mice $(n=3$; Huang et al., 1993) as a negative control. It is well established that there is a large population of nNOS-expressing neurons in the IPN, which lies just ventral to the VTA and was therefore well suited to act as a positive control (Vincent and Kimura, 1992; Rodrigo et al., 1994; Ascoli et al., 2008). The first antibody (Sigma Aldrich; N7155; AB_260795) failed to detect cell bodies and instead many processes were visible (Fig. 1A), which were also present in the nNOSdeficient tissue, suggesting that it was non-specific. The second antibody (Cell Signaling; 4234; AB_10694499) displayed some sparse immunoreactivity "spots" that could be mistaken for cell bodies within the VTA and SNc (Fig. 1B), which were also present in the nNOS-deficient tissue, suggesting that they were non-specific. The third antibody (Sigma Aldrich; N2280; AB_260754) exhibited clear immunolabelling of cell bodies in the wild-type tissue, which was completely absent in the nNOS-deficient tissue (Fig. 1C). In the wild-type tissue nNOS+ neurons were mosaically distributed throughout the SNc, and most notably in the parabrachial pigmented nucleus (PBP) and rostral linear nucleus (RLi) of the VTA. These were in close proximity to $\mathrm{TH}+$ 

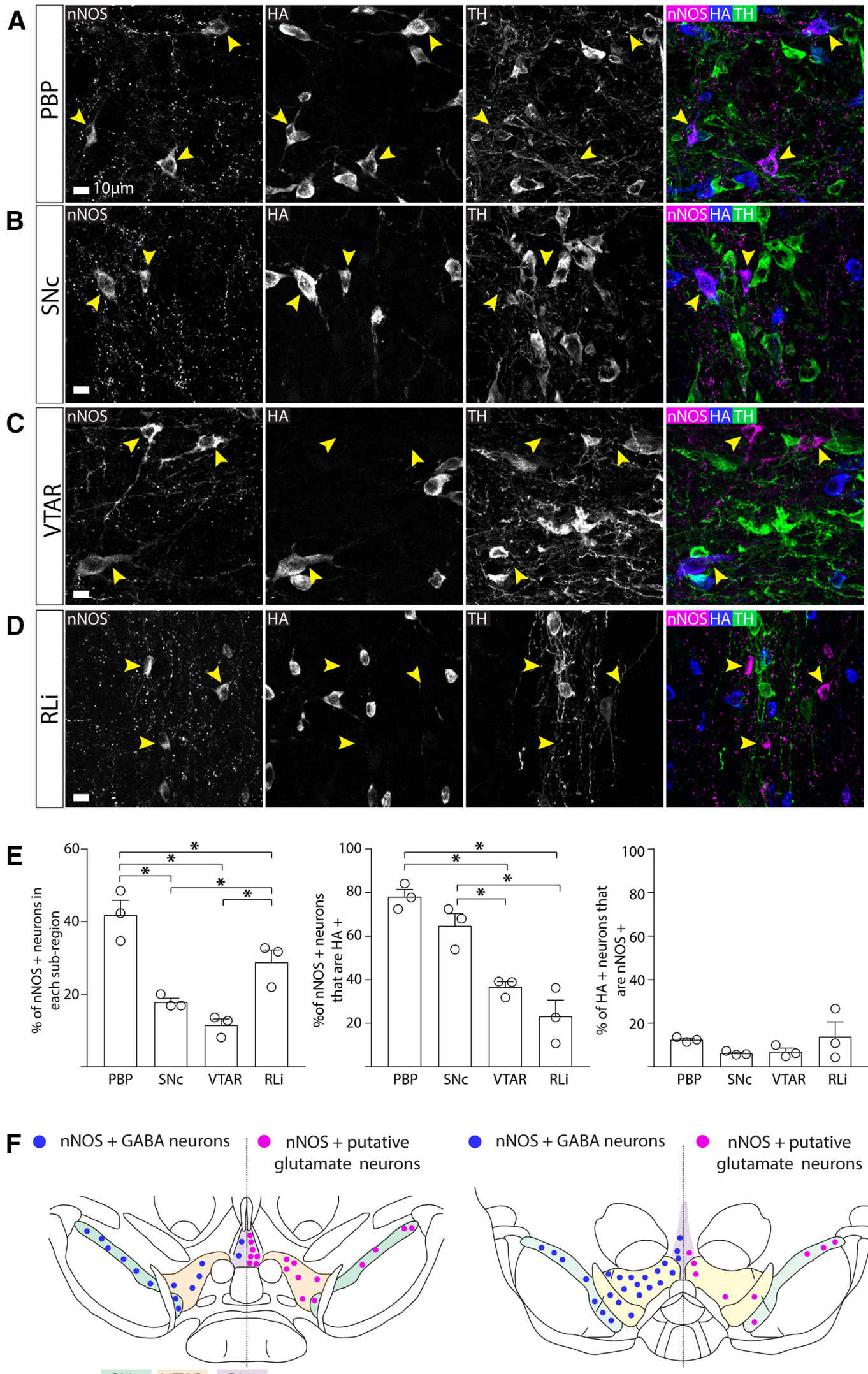
- nNOS + GABA neurons
- nNOS + putative glutamate neurons

SNC VTAR RLi

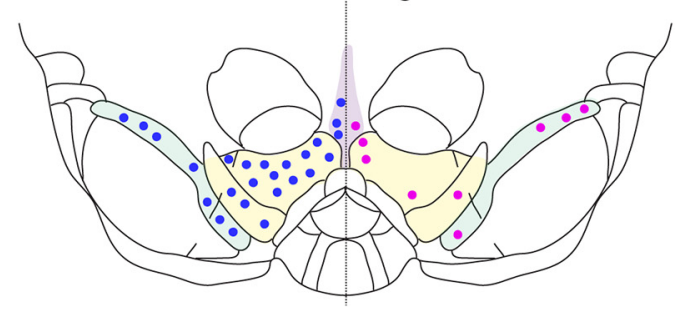

SNC PBP RLi

Figure 2. nNOS is mostly expressed in GABAergic, non-dopaminergic neurons in the PBP part of the VTA and SNc, and mostly in non-GABAergic, non-dopaminergic (putatively glutamatergic) neurons in the VTAR and RLi. $\boldsymbol{A}-\boldsymbol{D}$, Representative images of triple 
continued

immunolabelling for nNOS, HA, and TH, in the SNc and sub-regions of the VTA. Yellow arrows indicate nNOS+ neurons. $\boldsymbol{E}$, Graphs show the mean ( \pm SEM; $n=3$ mice, 1469 cells) and individual data points for percentage of $n N O S+$ cells localized in each region, percentage of nNOS + cells that colocalized with $\mathrm{HA}$, and the percentage of HA+ cells that were nNOS.$+ \boldsymbol{F}$, Schematic illustrating the localization of nNOS+/GABAergic neurons and nNOS+/glutamatergic neurons in the VTA and SNc. Yellow arrows indicate exemplar neurons; $* p<0.05$.

neurons, but there was no colocalization between nNOS and TH (Fig. 1C).

nNOS is mostly expressed in GABAergic, nondopaminergic neurons in the PBP part of the VTA and the SNc, and mostly in non-GABAergic, nondopaminergic (putatively glutamatergic) neurons in the VTAR and RLi

We next asked whether these nNOS+ neurons in the VTA and SNc were GABAergic. In the VTA and SNc, antibodies for markers of GABAergic identity (i.e., GABA, GAD, and VGAT) do not robustly label cell bodies. We, therefore, used VGATCre mice (Vong et al., 2011), where cre-recombinase is under the control of the promoter for VGAT, crossed with RiboTag mice (Sanz et al., 2009) which contains a floxed hemagglutinin (HA)-tagged exon in the RLp22 gene. The resulting offspring (VGATCre: RiboTag) exhibit robust HA expression in cell bodies in the VTA and SNc which is well suited to examining colocalization using immunolabelling (somewhat more so than standard GFP and tdTomato reporter lines, in our hands). Triple immunolabelling for $\mathrm{nNOS}$, HA, and TH was conducted in midbrain sections from VGATCre:RiboTag mice ( $n=3$ mice, 1420 neurons). Nuclei sub-regions were defined using $\mathrm{TH}$ immunolabelling and images from a mouse brain atlas (Franklin and Paxinos, 2008). All $\mathrm{nNOS}+$ and $\mathrm{HA}+$ neurons within each sub-region were counted. The number of nNOS + neurons varied in different sub-regions with the largest populations lying in the PBP of the VTA and the RLi, with smaller populations found in the SNc and VTAR (ANOVA: $F_{(3,8)}=22.33, p=$ 0.0003 ; Fig. $2 A-E$ ). nNOS + neurons were almost entirely absent in the interfascicular nucleus (IF) and the paranigral nucleus (PN) and therefore these sub-regions were not included in our analysis or further investigated.

Consistent with our first set of results, there was no colocalization between TH and nNOS. In contrast, colocalization between nNOS and HA was extensive, although it varied between different sub-regions (ANOVA: $F_{(3,8)}=$ 24.54, $p=0.0002$ ). In the PBP and SNc, the majority nNOS+ neurons were also $\mathrm{HA}+$, suggesting that nNOS+ neurons in these regions are mostly GABAergic (Fig. $2 A, B, E, F)$. In contrast, in more rostral sub-regions (i.e., the VTAR and RLi) the majority of nNOS + neurons were HA(and $\mathrm{TH}-$ ) and therefore putatively glutamatergic (Fig. $2 \mathrm{C}-\mathrm{F}$ ). Finally, the total proportion of $\mathrm{HA}+$ neurons that expressed nNOS was similar in each sub-region (ANOVA: $F_{(3,8)}=1.268, p=0.3489$; Fig. $\left.2 E\right)$, typically $<20 \%$, indicating that nNOS + neurons represent a sub-group of the overall GABAergic population in each of these subregions.

\section{AAV injection into the VTA and SNc of NOS1Cre \pm mice leads to expression of ChR2-mCherry in cell bodies in distinct regions depending on injection volume/position}

Having examined the neurochemical identity of nNOS+ neurons in the VTA and SNc, we next investigated their axonal projections. To do this, we did stereotaxic injections of AAV1-Ef1a-DIO-ChR2-mCherry into the midbrain of NOS1Cre \pm mice $(n=18)$. We have used this AAV previously in the midbrain and hypothalamus to obtain robust ChR2-mCherry expression with no apparent consequences for cell health (Viskaitis et al., 2017; Sandhu et al., 2018). We systematically varied the injection coordinates (see Materials and Methods) and then examined the degree of cell body expression of ChR2-mCherry within the $\mathrm{SNc}$ and VTA. We excluded mice that exhibited ChR2-mCherry expression in either the IPN or the SUM (both regions known to express nNOS; (Rodrigo et al., 1994; Gonzalez-Hernandez and Rodriguez, 2000). The extent of cell body expression fell into three groupings (Fig. $3 A$; Table 3): group 1 exhibited robust ChR2-mCherry cell body expression in the PBP, SNc, VTAR, and RLi; group 2 exhibited robust ChR2-mCherry cell body expression in the PBP, SNc, and a dorso-lateral boundary region of the VTAR (where we did not see cell bodies in group 1); group 3 exhibited robust ChR2-mCherry cell body expression only in the PBP and SNc. In all cases, cell bodies exhibited robust expression of ChR2mCherry, which was also often seen in long dendritic processes. Importantly, cell body and dendritic morphology appeared normal in neurons expressing mCherry (Fig. $3 B$ ), when compared to previous reports for GABA neurons in the VTA (Chieng et al., 2011; Margolis et al., 2012).

\section{When ChR2-mCherry expression was restricted to cell bodies in the PBP part of the VTA and the SNc, no axonal projections were found outside of the VTA and SNc}

For each mouse we conducted a full survey of the entire brain looking for ChR2-mCherry positive axonal projections. In brains from group 1 (which exhibited cell body labeling in the PBP, SNc, VTAR, and RLi), we observed extensive axonal projections in multiple regions (Fig. 4; Table 3), all shown previously to receive input from GABA and glutamate neurons in the VTA (Taylor et al., 2014). These projections were most dense in the ventral pallidum (VP), lateral hypothalamus (LH), and median raphe (MnR). In brains from group 2 (which exhibited cell body labeling in the PBP, SNc, and dorso-lateral part of the VTAR) we only reliably observed very sparse processes in the $\mathrm{LH}$ (Fig. 4; Table 3). In brains from group 3 (which exhibited 
A

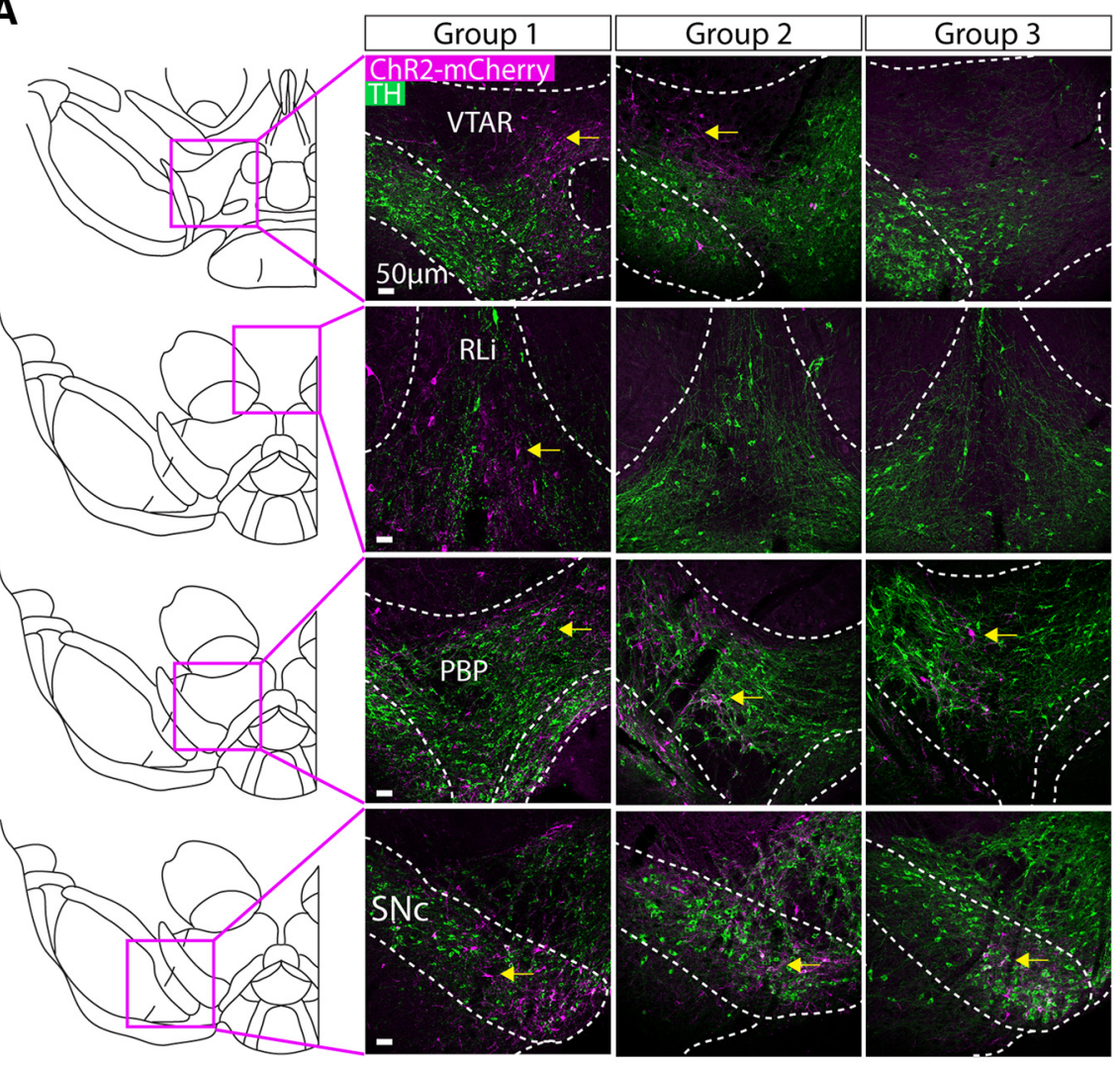

B

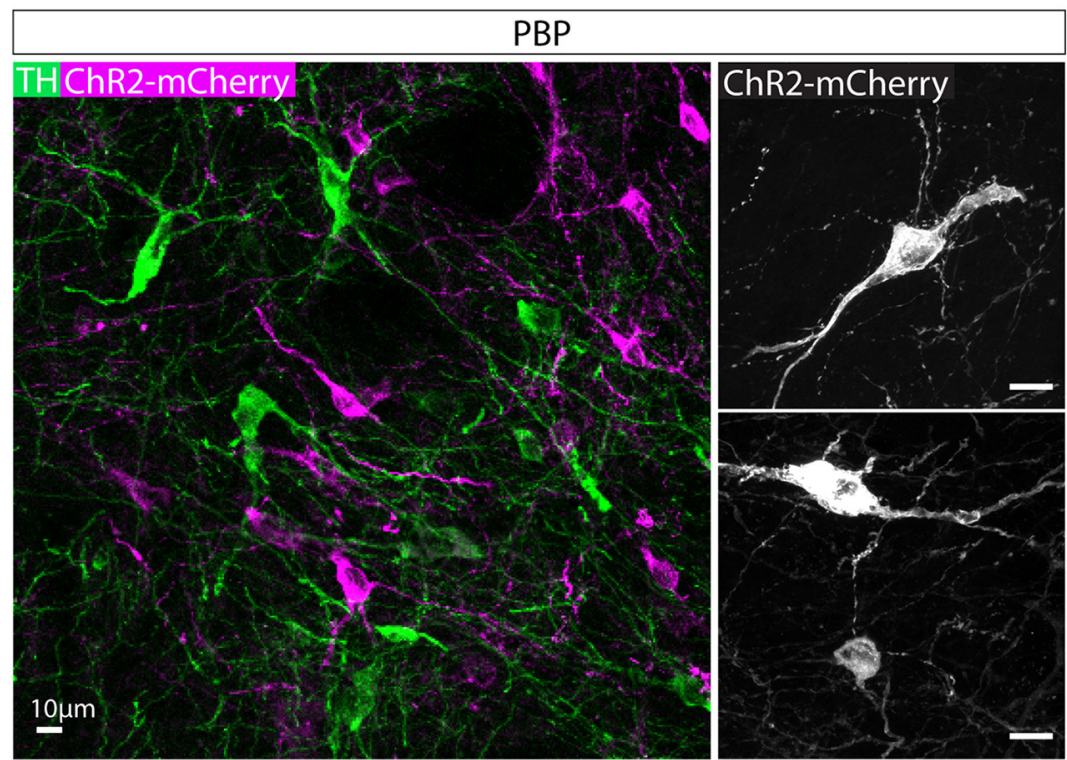

Figure 3. AAV injection into the VTA and SNc of NOS1cre \pm mice lead to expression of ChR2-mCherry in cell bodies in distinct regions depending on injection volume/position. $\boldsymbol{A}$, Representative images of ChR2-mCherry (magenta) and TH (green) in cell bodies for each injected group. Mice were grouped based on the distribution of ChR2-mCherry expressing cell bodies (yellow arrows indicate sub-regions where robust cell body expression was observed). Group 1 exhibited expression in the VTAR, RLi, PBP and SNc, group 2 exhibited expression in the dorso-lateral VTAR, PBP, and SNc, and group 3 exhibited expression that was restricted to the PBP and SNc (Table 3). B, Higher magnification, representative images illustrate the robust expression of ChR2-mCherry (magenta) in cell bodies and dendrites intermingled with TH (green)-expressing neurons. Right-hand images show higher magnification images of ChR2-mCherry-expressing neurons. 
Table 3. ChR2-mCherry expression in cell bodies and axon terminals following VTA/SNc AAV injections in NOS1Cre-/+ mice

\begin{tabular}{|c|c|c|c|c|c|c|c|c|c|c|}
\hline \multirow[b]{2}{*}{ Injection number } & \multicolumn{4}{|c|}{ Group 1} & \multicolumn{3}{|c|}{ Group 2} & \multicolumn{3}{|c|}{ Group 3} \\
\hline & 7 & 8 & 9 & 10 & 13 & 14 & 15 & 16 & 17 & 18 \\
\hline \multicolumn{11}{|l|}{ Cell bodies } \\
\hline VTAR & + & ++ & ++ & +++ & +++ & +++ & +++ & & + & + \\
\hline RLi & +++ & +++ & +++ & +++ & & & & & & \\
\hline PBP & +++ & +++ & +++ & +++ & +++ & +++ & +++ & ++ & +++ & ++ \\
\hline SNc & +++ & +++ & +++ & +++ & +++ & +++ & +++ & ++ & +++ & + \\
\hline
\end{tabular}

Axonal projections

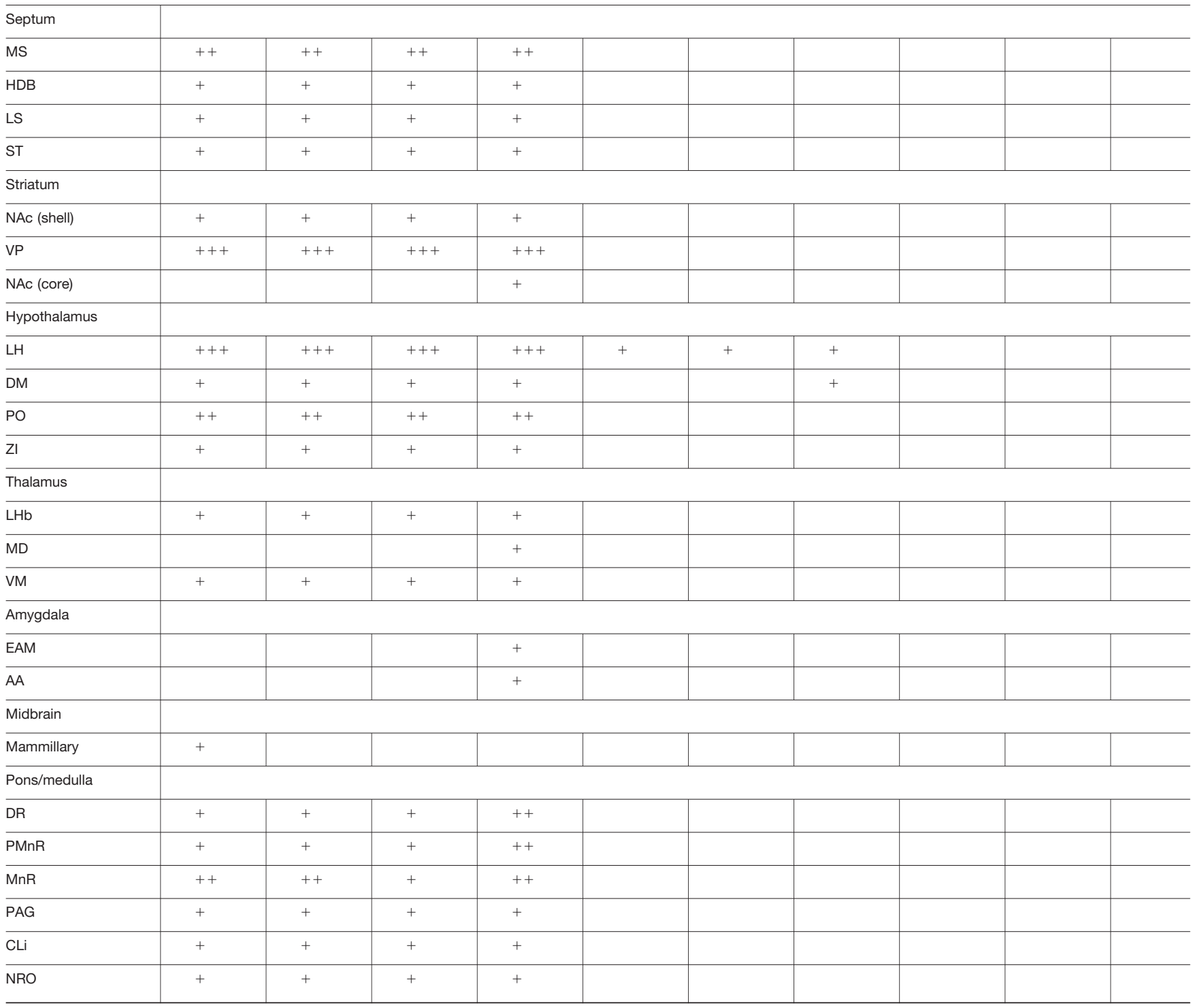

ChR2-mCherry expression density: +, very sparse expression; ++, modest expression; +++ , dense expression. AA, amygdaloid area; CLi, caudal linear nucleus; DM, dorsomedial hypothalamic nucleus; DR, dorsal raphe nucleus; EAM, extended amygdala, medial part; HDB, horizontal limb of the diagonal band of Broca; LH, lateral hypothalamus; LHb, lateral habenula; LS, lateral septum; MD, dorsomedial nucleus of the hypothalamus; Mm, mammillary bodies; MnR, median raphe nucleus; MS, medial septum; NAc, nucleus accumbens; NRO, nucleus raphe obscurus PAG, periaqueductal gray; PBP, parabrachial pigmented nucleus; PMnR, paramedian raphe nucleus; PO, preoptic area; RLi, rostral linear nucleus; SNr, substantia nigra pars reticulata; ST, stria terminalis; VM, ventromedial thalamus; VP, ventral pallidum; VTAR, rostral ventral tegmental area; Zl, zona inserta. ${ }^{\text {, }}$, cell bodies were restricted to the dorso-lateral boundary region of the VTAR and this was not seen in group 1 or group 3.

robust cell body labeling only in the PBP and SNc), we did not observe any axonal projections outside of the VTA and SNc (Fig. 4; Table 3). On the basis of these expression patterns we can, therefore, draw two main conclusions.
First, NOS1Cre+ neurons in the PBP and SNc do not send axonal projections outside of the VTA and SNC. Second, NOS1Cre+ neurons in the VTAR and RLi send extensive projections to multiple regions, including the 


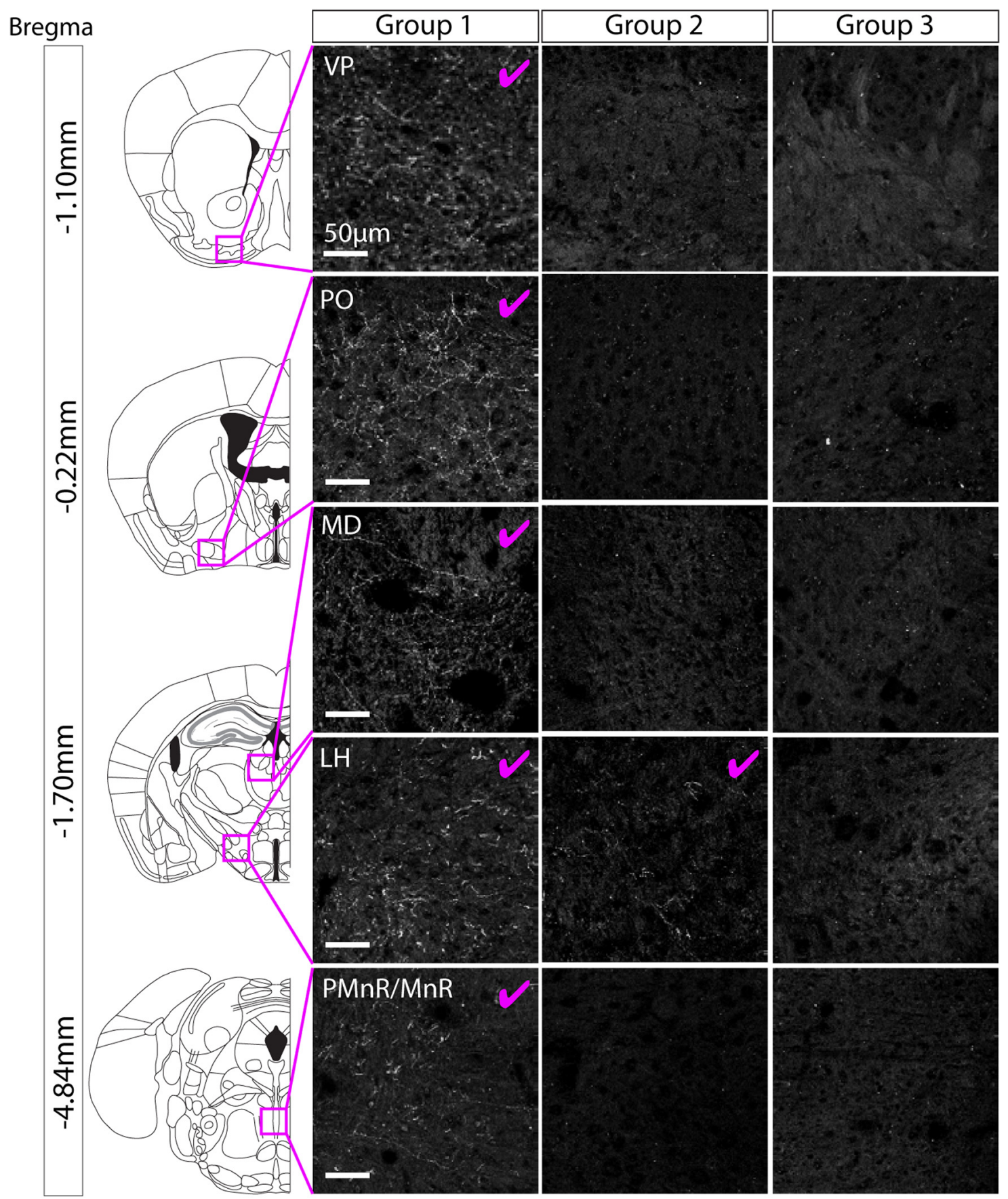

Figure 4. When ChR2-mCherry expression was restricted to cell bodies in the PBP part of the VTA and the SNc, no axonal projections were found outside of the VTA and SNc. Representative images of axon-expressed ChR2-mCherry for each group. group 1 exhibited extensive projections (for full summary, see Table 3) to multiple regions. Images are shown for the VP, PO, MD, LH, IPN, and $\mathrm{PMnR} / \mathrm{MnR}$, where the most extensive axonal expression was observed (pink tick indicates robust axonal expression). Group 2 exhibited sparse projections that were limited to the LH. Group 3 (which had cell body labeling restricted to the PBP and SNc) did not exhibit any axonal expression outside of the VTA and SNc.

VP, LH and MnR. All of these regions are known to receive input from the RLi (Del-Fava et al., 2007). It should be noted that in the case of group 2, where some sparse fibers were observed the LH, the cell body labeling in these cases was restricted to the dorso-lateral part of the VTAR only. In contrast in group 1 cell body labeling was observed throughout the VTAR.
Cell body expression of ChR2-mCherry was colocalized with nNOS immunolabelling in the VTA, but in the SNc some neurons were $\mathrm{TH}+$

We next examined the degree of colocalization between ChR2-mCherry, nNOS, and TH in cell bodies in the PBP, SNc, VTAR, and RLi ( $n=3-5$ mice, 554 neurons). We conducted immunolabelling for $\mathrm{nNOS}$ and $\mathrm{TH}$ and 
A

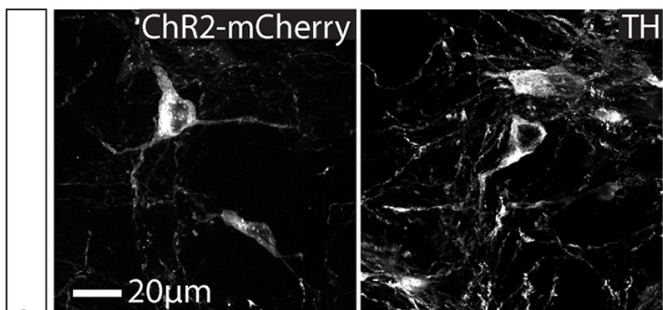

$\frac{\hat{m}}{0}$

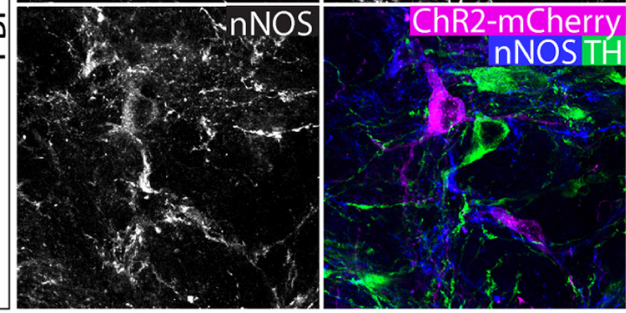

B

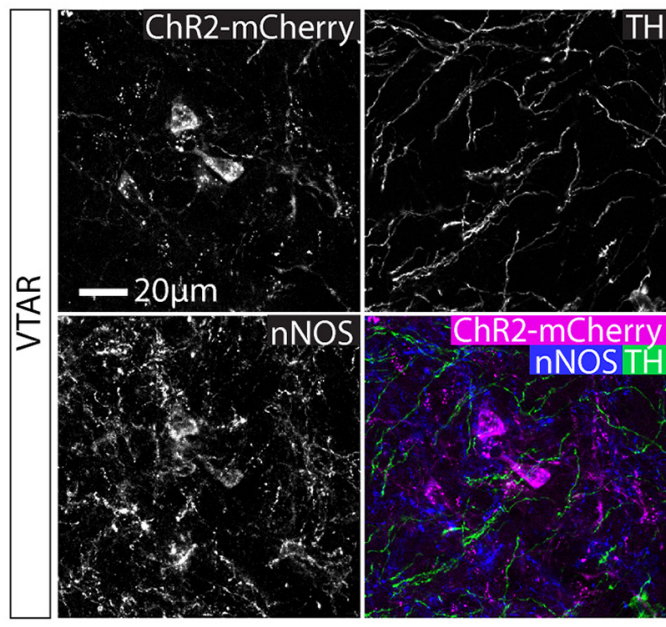

C

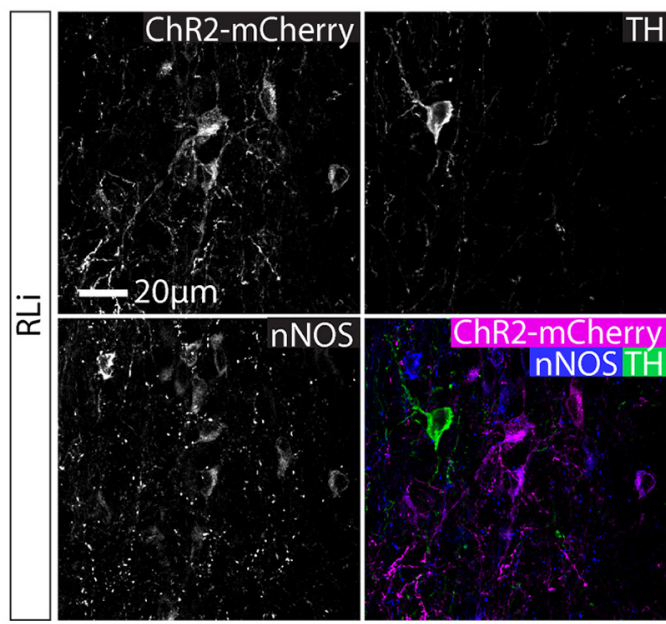

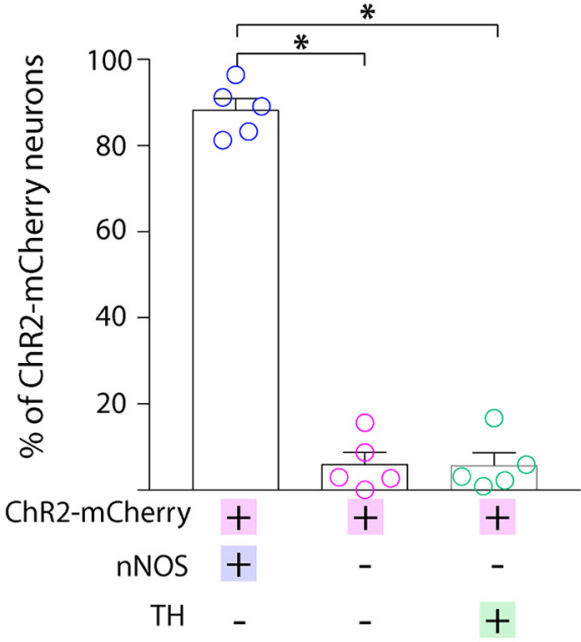

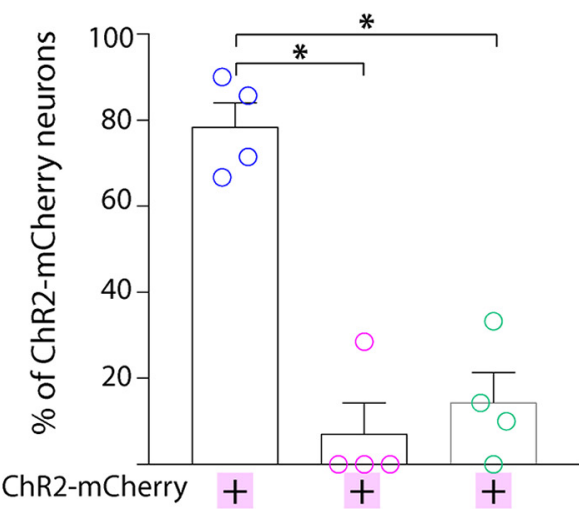

ChR2-mCherry + nNOS

$\mathrm{TH}$

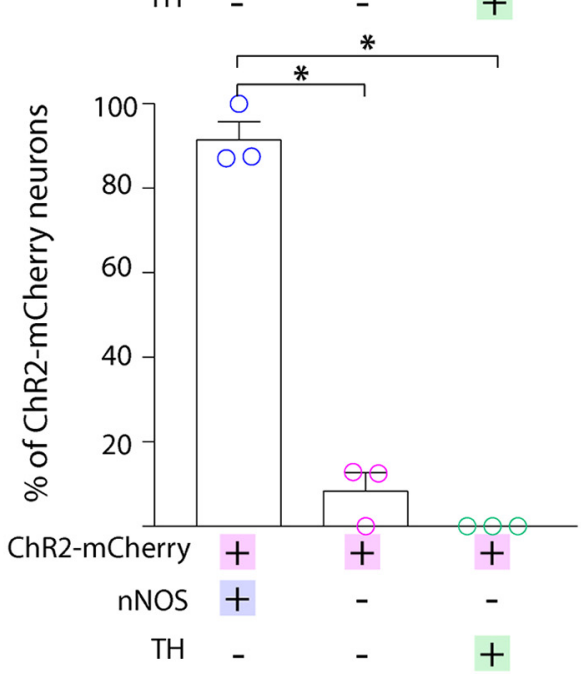

Figure 5. Cell body expression of ChR2-mCherry was colocalized with nNOS immunolabelling in the VTA. $\boldsymbol{A}$, Representative images of triple immunolabelling for ChR2-mCherry, nNOS, TH in the PBP. Graph shows the mean ( \pm SEM) and individual data points for percentage of ChR2-mCherry that were colocalized with nNOS and/or TH (230 ChR2-mCherry+ cells, five mice). Almost all $\mathrm{ChR} 2-\mathrm{mCherry}+$ neurons were nNOS + and $\mathrm{TH}-$. B , Representative images of triple immunolabelling for ChR2-mCherry, nNOS, TH in the VTAR. Graph shows the mean ( \pm SEM) and individual data points for percentage of ChR2-mCherry that were colocalized with nNOS and/or TH (40 ChR2-mCherry+ cells, four mice). Almost all ChR2-mCherry+ neurons were nNOS + and TH-. C, Representative images of triple immunolabelling for ChR2-mCherry, nNOS, TH in the RLi part of the VTA. Graph shows the mean ( \pm SEM) and individual data points for percentage of ChR2-mCherry that were colocalized with nNOS and/or TH (155 ChR2-mCherry+ cells, three mice). Almost all ChR2-mCherry+ neurons were nNOS + and $\mathrm{TH}-; * p<0.05$. 
A

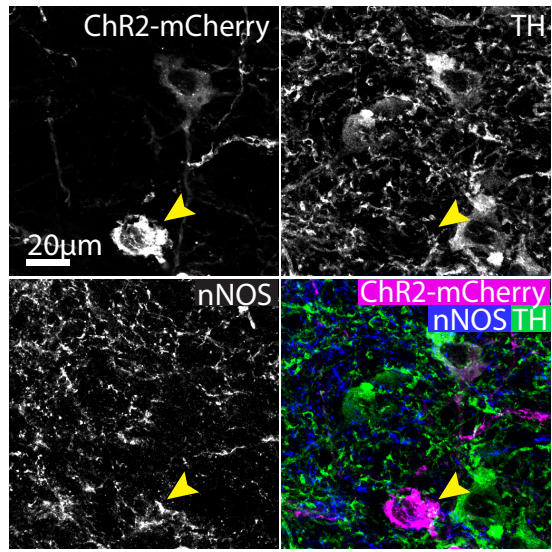

B

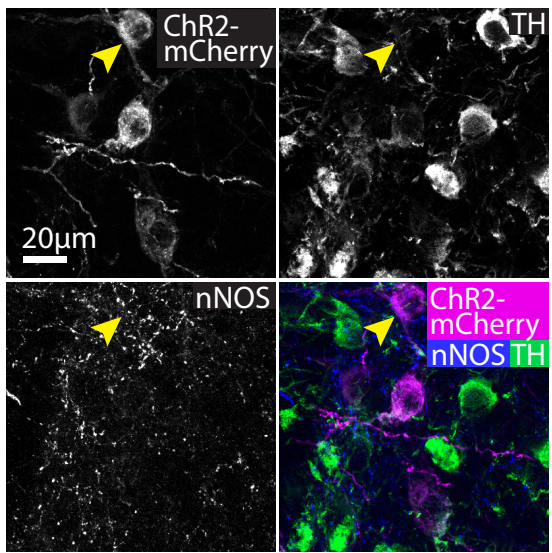

C

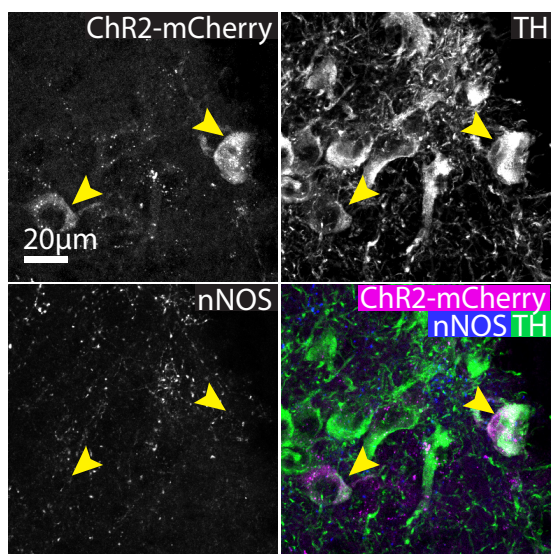

D

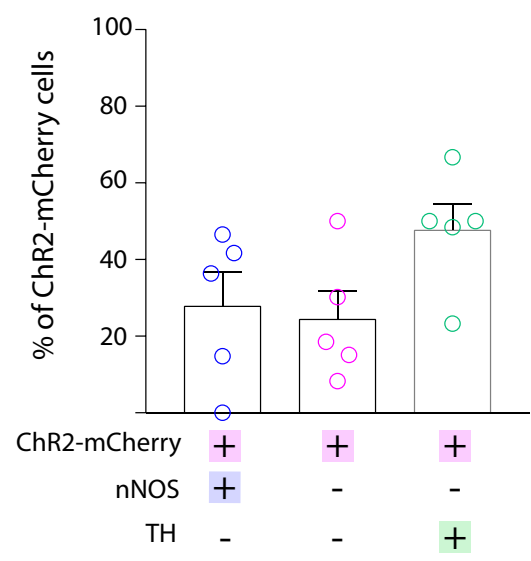

Figure 6. Cell body expression of ChR2-mCherry was mostly colocalised with either nNOS or TH in the SNc. Representative images of triple immunolabelling for ChR2-mCherry, nNOS, TH in the SNc, showing exemplar cells exhibiting either: $\boldsymbol{A}$, colocalisation of nNOS and ChR2-mCherry, but not TH. $\boldsymbol{B}$, expression of ChR2-mCherry, but neither nNOS nor TH. or $\boldsymbol{C}$, co-localisation of ChR2-mCherry and TH, but not nNOS. $\boldsymbol{D}$, Graph shows the mean (+SEM) and individual data points for percentage of ChR2-mCherry that were colocalised with nNOS and/or TH (129 ChR2-mCherry+ cells, five mice). Most ChR2-mCherry+ neurons were either nNOS + or $\mathrm{TH}+$. Yellow arrows indicate exemplar neurons.

examined colocalization with ChR2-mCherry. In the PBP $\left(n=5\right.$ mice; ANOVA: $\left.F_{(2,12)}=290.0, p<0.0001\right)$, VTAR $(n$ $=4$ mice; ANOVA: $\left.F_{(2,9)}=35.27, p<0.0001\right)$, and RLi $(n$ $=3$ mice; ANOVA: $\left.F_{(2,6)}=213.9, p<0.0001\right)$ nucleus, almost all ChR2-mCherry + cells were nNOS + and $\mathrm{TH}-$ (Fig. 5A-C).

In contrast, in the SNc similar numbers of neurons were ChR2-mCherry + and/or nNOS + and/or TH+ (ANOVA: $\left.F_{(2,12)}=2.627, p=0.1132\right)$. Although a majority of the ChR2-mCherry + cells were nNOS + (Fig. 6), surprisingly, around half of the ChR2-mCherry+ neurons in the SNc were $\mathrm{TH}+$ (and nNOS-; Fig. 6). As observed in both the wild-type and VGATCre:RiboTag mice, nNOS antibody immunolabelling did not colocalize with TH in the SNc. It is possible, however, that these neurons appear immunonegative for nNOS because they are either expressing very low levels of the enzyme (so that it is not detectable with the nNOS antibody), or that nNOS mRNA is being transcribed but the protein is not being synthesized currently. Because this result was somewhat unexpected, we wanted to replicate it with a different AAV. In this case, we injected AAV-hsyn-flex-mCherry into the SNc and lateral VTA. In cases where cell body labeling was restricted to neurons in the SNc and lateral VTA $(n=2)$, we again observed mCherry+ neurons that were also $\mathrm{TH}+$, and we could not detect any axonal projections outside of the SNc and VTA. Furthermore, we also found that in all cases examined these $\mathrm{TH}+$ neurons co-expressed aromatic L-amino acid decarboxylase (AADC) and the dopamine transporter (DAT), suggesting that they might be dopamine releasing (Fig. 7).

\section{Axonal expression of ChR2-mCherry+ was colocalized with GABAergic synaptic boutons in the VTA and SNc}

Taken together, our findings suggest that nNOS+ neurons in the PBP and SNc are GABAergic and do not project outside the VTA and SNc. To further examine their neurochemical identity, we examined single $z$-plane images of tissue immunolabelled for VGAT and TH. In the VTA and SNc, although VGAT antibodies do not resolve cell bodies well (as discussed earlier) they can reliably label processes, include putative presynaptic boutons. In the VTA, we commonly observed VGAT + puncta colocalized with ChR2-mCherry and in close proximity to, but not colocalizing with, $\mathrm{TH}+$ processes (Fig. 8A). This is consistent with the possibility that nNOS+ interneurons form inhibitory synapses onto dopamine neurons. In addition, 


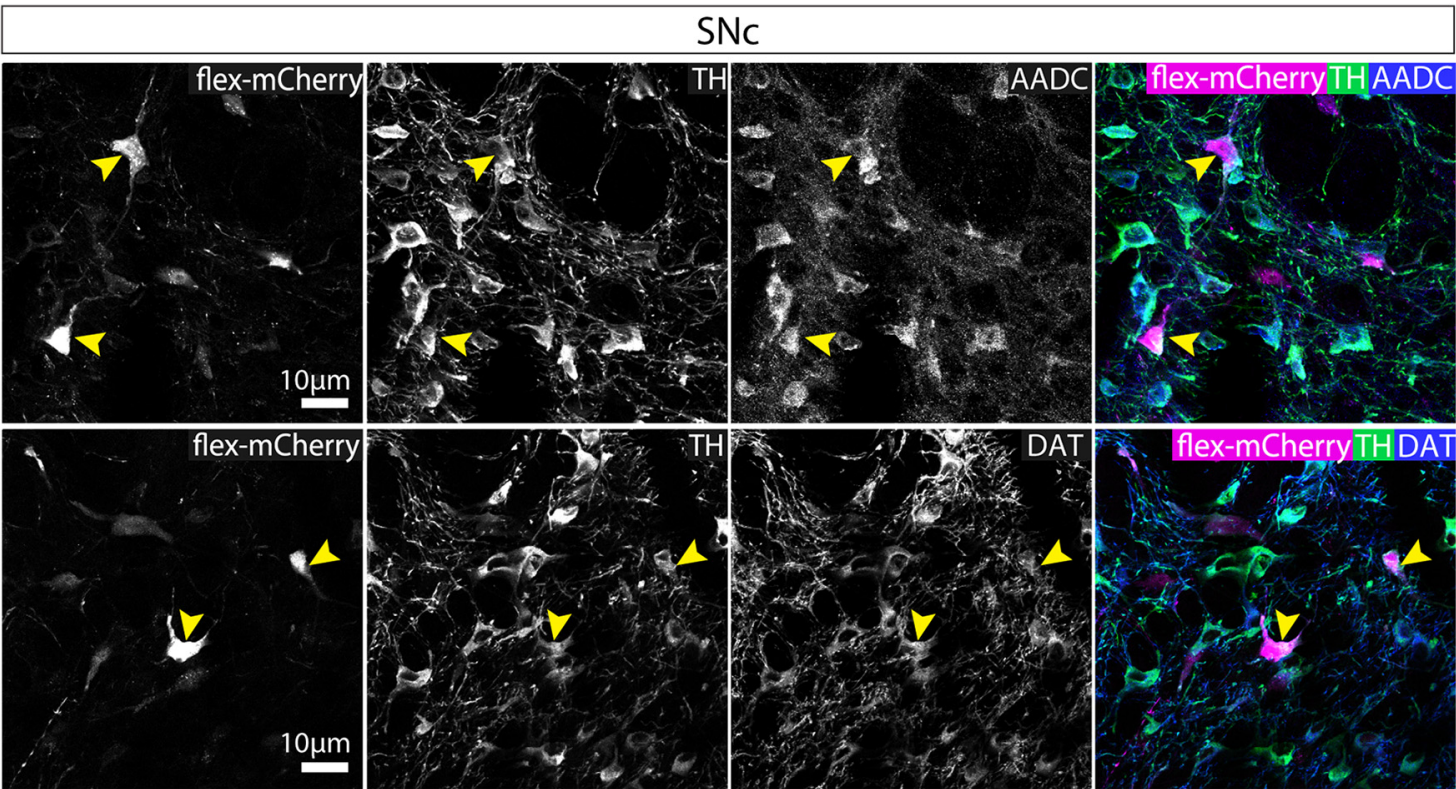

Figure 7. mCherry-expressing neurons that were also $\mathrm{TH}+$, co-expressed AADC and DAT. Representative images of triple immunolabelling for mCherry, TH and AADC or mCherry, TH, and DAT. mCherry+ neurons that were TH+ were also AADC + and DAT + . Yellow arrows indicate exemplar cell bodies, exhibiting triple colocalization.

in the SNc, we were able to locate some ChR2-mCherry+ fibers that were also colocalized with $\mathrm{VGAT}+/ \mathrm{TH}+$ puncta (Fig. 8B).

\section{Axonal expression of ChR2-mCherry was colocalized with glutamatergic synaptic boutons in the VP and MnR}

The VP is the area that received the most prominent input from the nNOS+ neurons in the RLi nucleus, consistent with non-cell type-specific anterograde tracing approaches (Del-Fava et al., 2007). To examine this innervation in more detail, VP containing sections were immunolabelled for substance $\mathrm{P}$ (which delineates the VP) and either VGluT2 or VGAT. It can be clearly seen that ChR2-mCherry+ fibers were more prevalent in the VP (substance $\mathrm{P}+$ region) compared to the horizontal limb of the diagonal band of Broca (HDB) and shell of the NAc (areas that receive sparse innervation; Fig. 9A). This innervation is present throughout the extent of the VP. ChR2-mCherry+ puncta could be clearly visualised among substance $\mathrm{P}+$ puncta, and were commonly colocalized with VGluT2 + puncta (Fig. 9B). This is consistent with our observation that these projections originate mostly from cell bodies in the RLi and VTAR that are VGAT-/TH- and therefore putatively glutamatergic. Indeed, when we examined VGluT2 and ChR2-mCherry colocalization in the RLi, we observed some VGluT2+ cell bodies (as for GABAergic markers, it can be difficult to resolve cell bodies with antibodies for markers of glutamatergic neurons in the VTA) that were ChR2mCherry + , consistent with our hypothesis that this is a predominantly glutamatergic population (Fig. 9C). Lastly, when we conducted immunolabelling for VGAT, we occasionally observed colocalization with ChR2mCherry+ puncta, but these were less common than for VGluT2 (Fig. 9D).
A second region that received extensive input was the MnR. Immunolabelling for serotonin $(5-\mathrm{HT})$ revealed ChR2mCherry + terminals often in close proximity $5-\mathrm{HT}+$ neurons. (Fig. 10A). Similar to the VP, VGluT2+ (Fig. 10B) and VGAT+ (Fig. 10C) puncta colocalized with ChR2-mCherry+ puncta in single $z$-plane images.

\section{Discussion}

Previous investigations of nNOS expression in the VTA and $\mathrm{SNc}$ have produced discrepant results with respect to the extent of its expression, which sub-regions within the VTA and SNc it is expressed in, and the degree of coexpression by dopamine neurons (Vincent and Kimura, 1992; Rodrigo et al., 1994; Gonzalez-Hernandez and Rodriguez, 2000; Klejbor et al., 2004; Gotti et al., 2005; Cavalcanti-Kwiatkoski et al., 2010; Mitkovski et al., 2012). We hypothesized that this variation in the literature was in part due to the use of different antibodies not validated specifically for the VTA and SNc. Consistent with this, we found immunolabelling absent in control tissue from nNOS-deficient mice. This highlights the importance of validating antibodies. Using a validated antibody, we show that nNOS+ neurons are present in the SNc, VTAR, PBP, and RLi, but not other parts of the VTA, including the $\mathrm{PN}$. In addition, we show that nNOS + neurons in the SNc and PBP are largely GABAergic, whereas those located in the RLi and VTAR are largely glutamatergic. These GABAergic neurons appear to be interneurons: despite the high levels of expression of an anterograde tracer in their cell bodies, we could not detect any axonal projections outside of the VTA and SNc. We also observed at the light microscope level these neurons making, what appeared to be, local GABAergic synaptic boutons, but this would need to be confirmed anatomically and functionally using electron microscopy and electrophysiology 
A
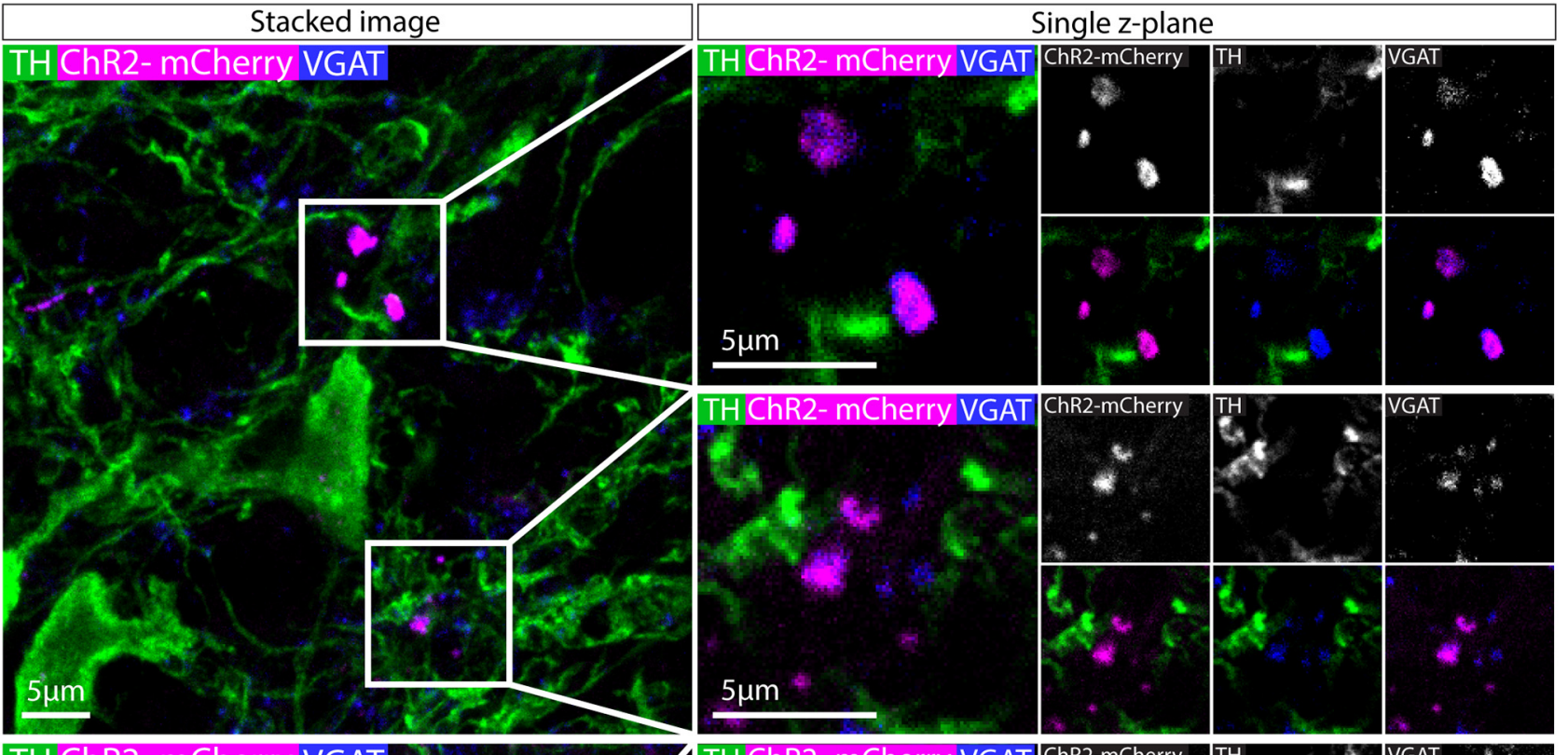

B
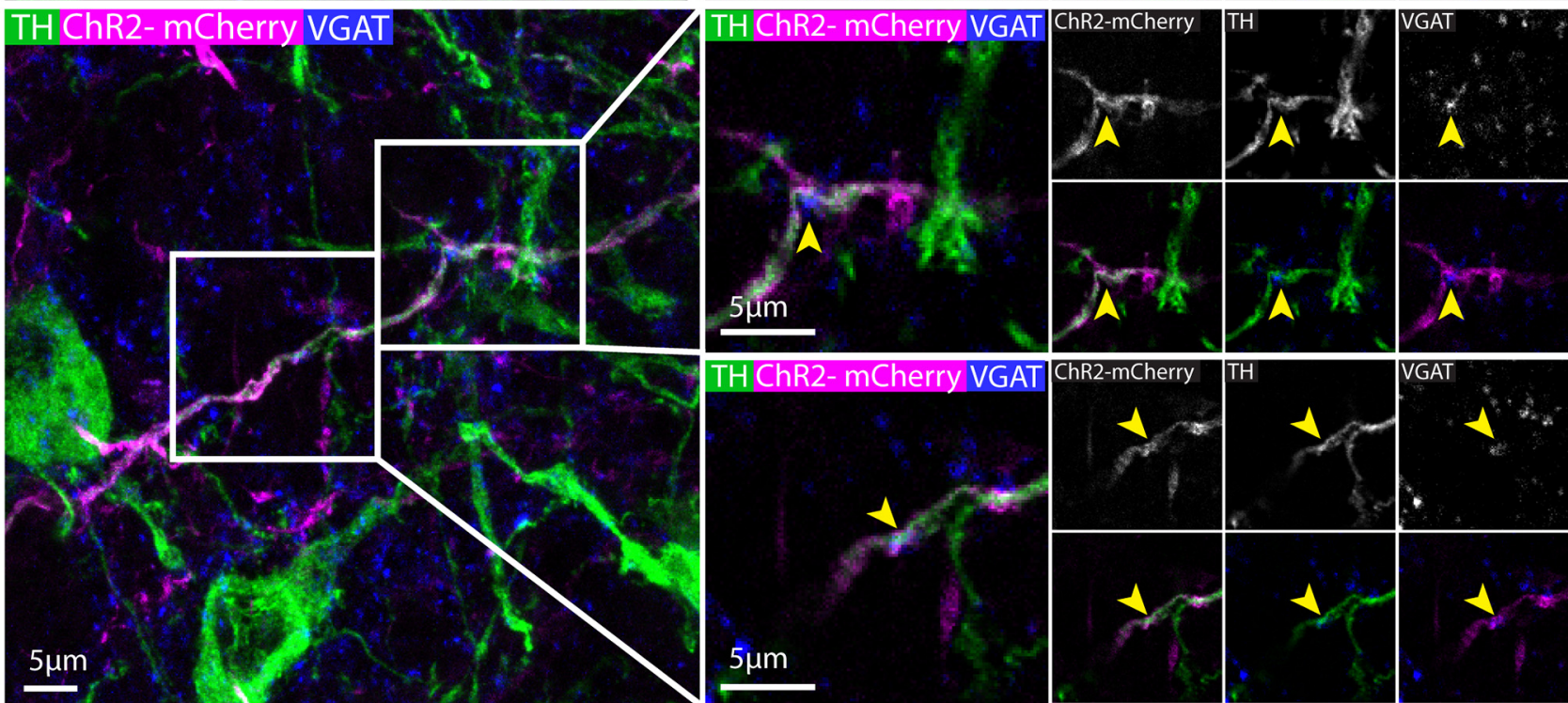

Figure 8. Axonal expression of ChR2-mCherry+ was colocalized with GABAergic synaptic boutons in the VTA and SNc. $\boldsymbol{A}$, Representative images of immunolabelling for ChR2-mCherry, VGAT, and TH in the PBP. ChR2-mCherry colocalizes with VGAT puncta in a single $z$-plane image suggesting the presence of GABAergic synapses. $\boldsymbol{B}$, Representative images of immunolabelling for ChR2-mCherry, VGAT, and TH in the SNc. ChR2-mCherry colocalizes with VGAT puncta in a single z-plane image suggesting the presence of GABAergic synapses. These puncta are also often $\mathrm{TH}+$. Yellow arrows indicate exemplar puncta.

respectively. Across these regions, nNOS+ neurons make up $<10 \%$ of the total GABA neuron population. In contrast, we found that nNOS+/glutamatergic neurons sent extensive projections to several regions, including the VP, LH and MnR.

Previously, it has been demonstrated that GABA neurons in the VTA make anatomically-defined local synaptic connections with dopamine and non-dopamine neurons in the VTA (Omelchenko and Sesack, 2009). Moreover, functional optogenetic stimulation of VTA GABA neurons can evoke fast GABAA-receptor-mediated synaptic currents in dopamine neurons in the VTA (Tan et al., 2012; van Zessen et al., 2012). Activation of this local GABAergic microcircuit can generate a conditioned place aver- sion and reduce food consumption (Tan et al., 2012; van Zessen et al., 2012). It was not clear, however, whether the GABA neurons that made these local synaptic connections were also the same GABA neurons that send long-range projections to other regions such as the striatum (Brown et al., 2012; Taylor et al., 2014). Our findings suggest that at least one subset of these neurons are local GABAergic interneurons. Moreover, because these neurons have a distinct molecular identity (i.e., nNOS expression), they are experimentally tractable (e.g., by using cell type-specific functional and anatomic techniques in NOS1Cre mice). This approach could be further refined using intersectional genetics (e.g., to limit expressionbased GABAergic or glutamatergic identity). A number of 
A

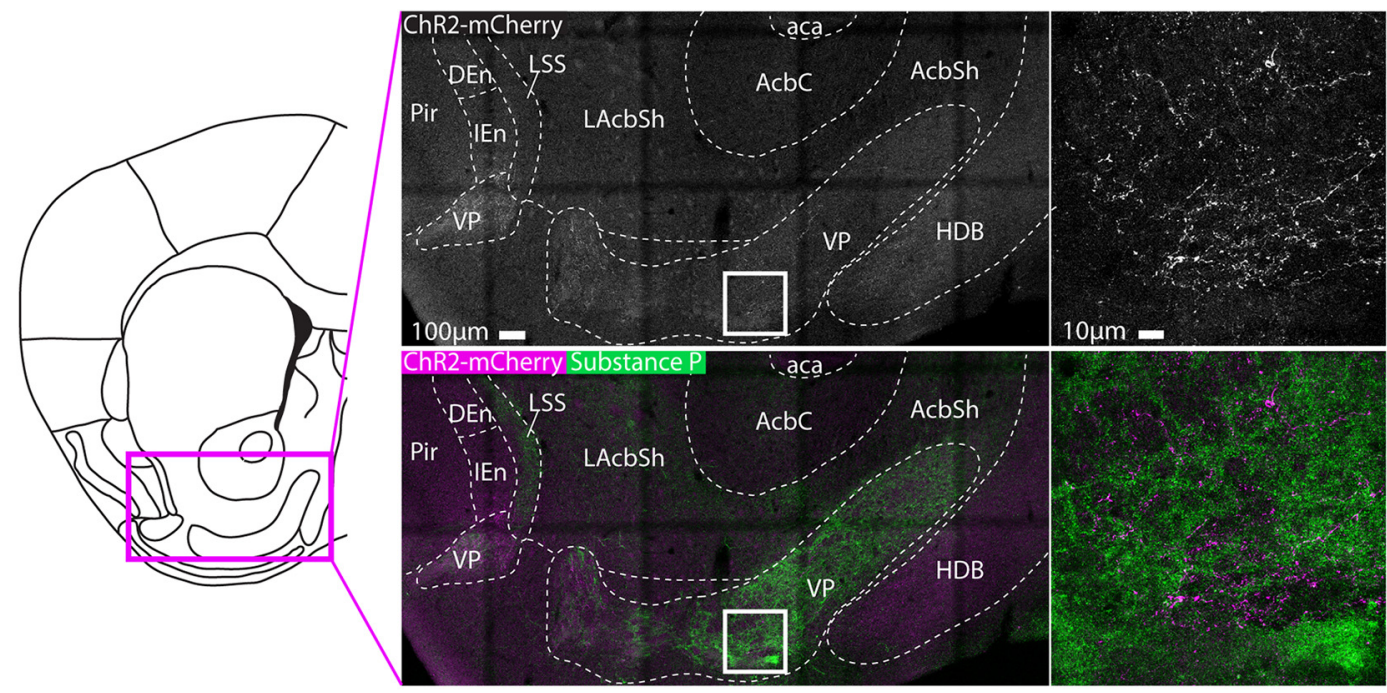

B

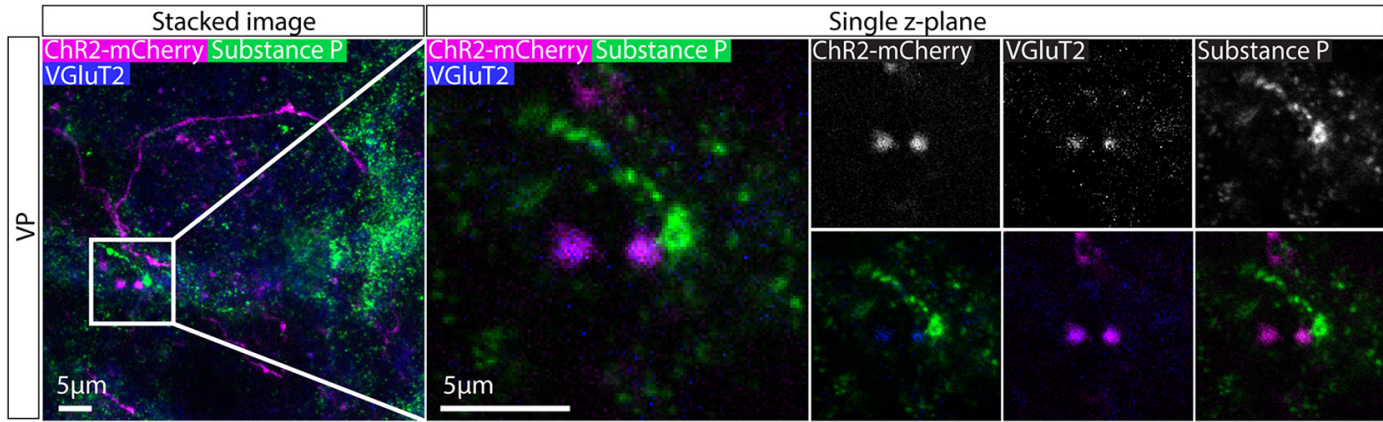

C

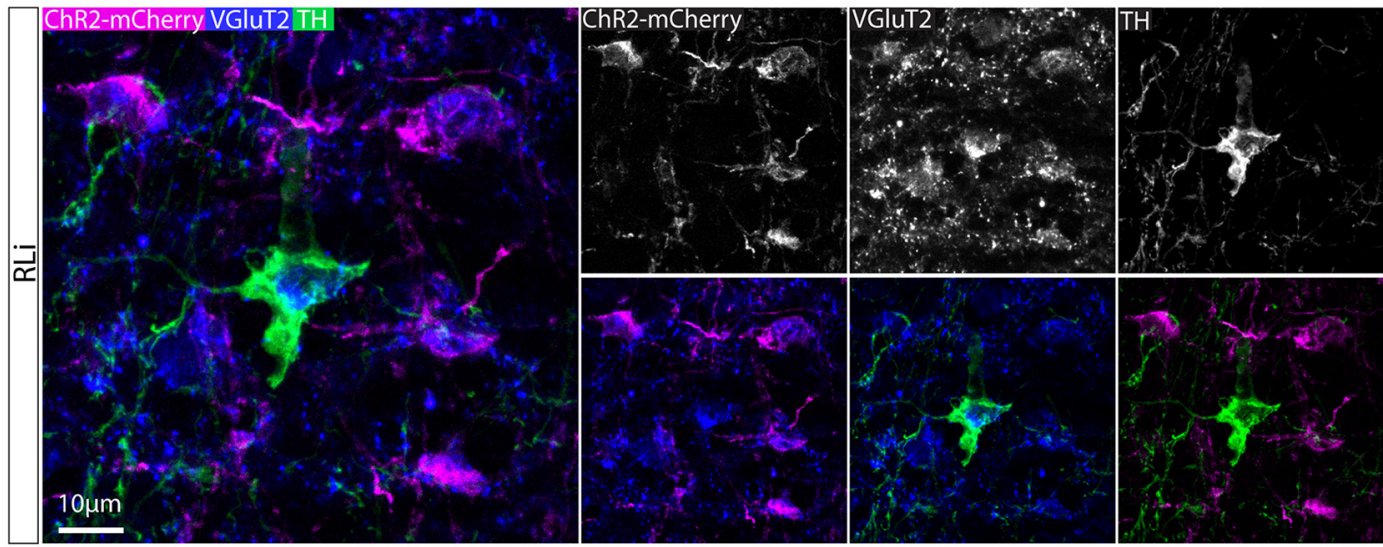

D

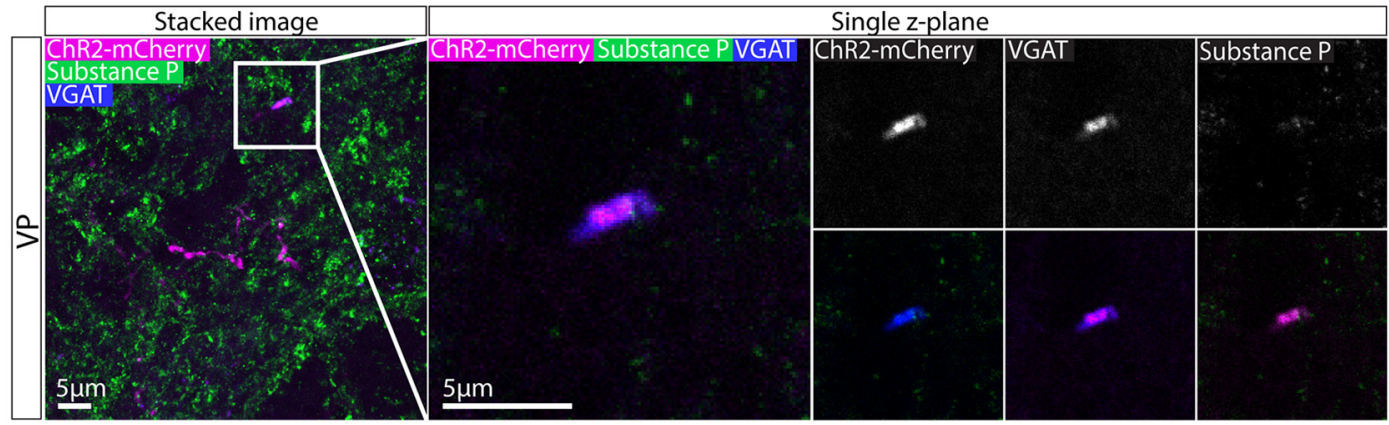

Figure 9. Axonal expression of ChR2-mCherry was colocalized with glutamatergic synaptic boutons in the VP. $\boldsymbol{A}$, Representative images of immunolabelling for ChR2-mCherry and substance $\mathrm{P}$ (which is highly expressed in the VP). Extensive innervation was observed in the VP compared to the neighboring parts of the NAc and septum. $\boldsymbol{B}$, High-magnification representative images of immunolabelling for ChR2-mCherry, substance P, and VGluT2 in the VP. Colocalization between ChR2-mCherry andVGluT2 puncta 


\section{continued}

can be seen in single $z$-plane images, suggesting that these projections are glutamatergic. $\mathbf{C}$, Representative images of immunolabelling for ChR2-mCherry, VGluT2, and TH, in the RLi, occasionally also revealed cell bodies that expressed VGluT2. D, Highmagnification representative images of immunolabelling for ChR2-mCherry, substance P, and VGAT in the VP. On some occasions, colocalization between ChR2-mCherry and VGAT puncta was observed in single z-plane images, suggesting that some these projections are also be GABAergic.

technical considerations must be taken into account with respect to this conclusion. Firstly, it may be that their axons did not readily transport the fluorescent markers that we used and/or the expression of those markers caused some axonal damage to the neurons. Secondly, although we were unable to detect any axonal projections of these neurons outside of the VTA and SNc, it remains possible that they send some sparse projections which we overlooked, despite very careful inspection of whole brains. There are several reasons why we consider these possibilities to be unlikely. First, we carefully examined neurons for overall health and they appeared normal. Moreover, we have previously used the same AAV to label dopamine neurons in the VTA and hypothalamic neurons without any detectable effects on morphology, physiology, or behavior (Viskaitis et al., 2017; Sandhu et al., 2018). Second, nNOS + neurons in the VTAR and RLi did exhibit extensive axonal projections, suggesting that mCherry/ChR2 can be visualised in the axons of a neighboring (in parts anatomically overlapping) population. Moreover, these neurons exhibited similar levels of cell body and dendritic labeling when compared to nNOS+
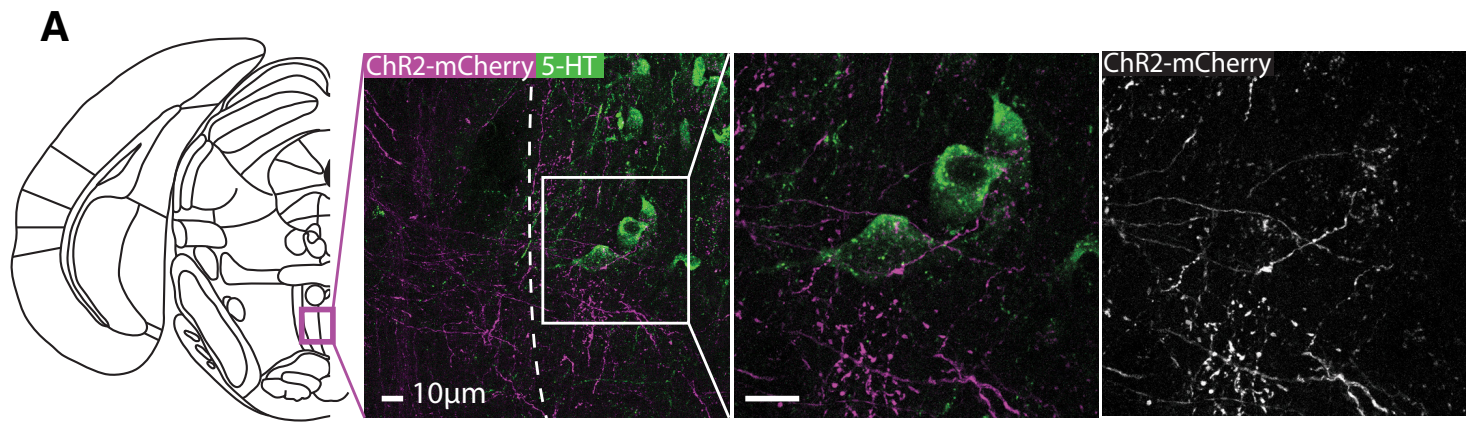

$\mathbf{B}$
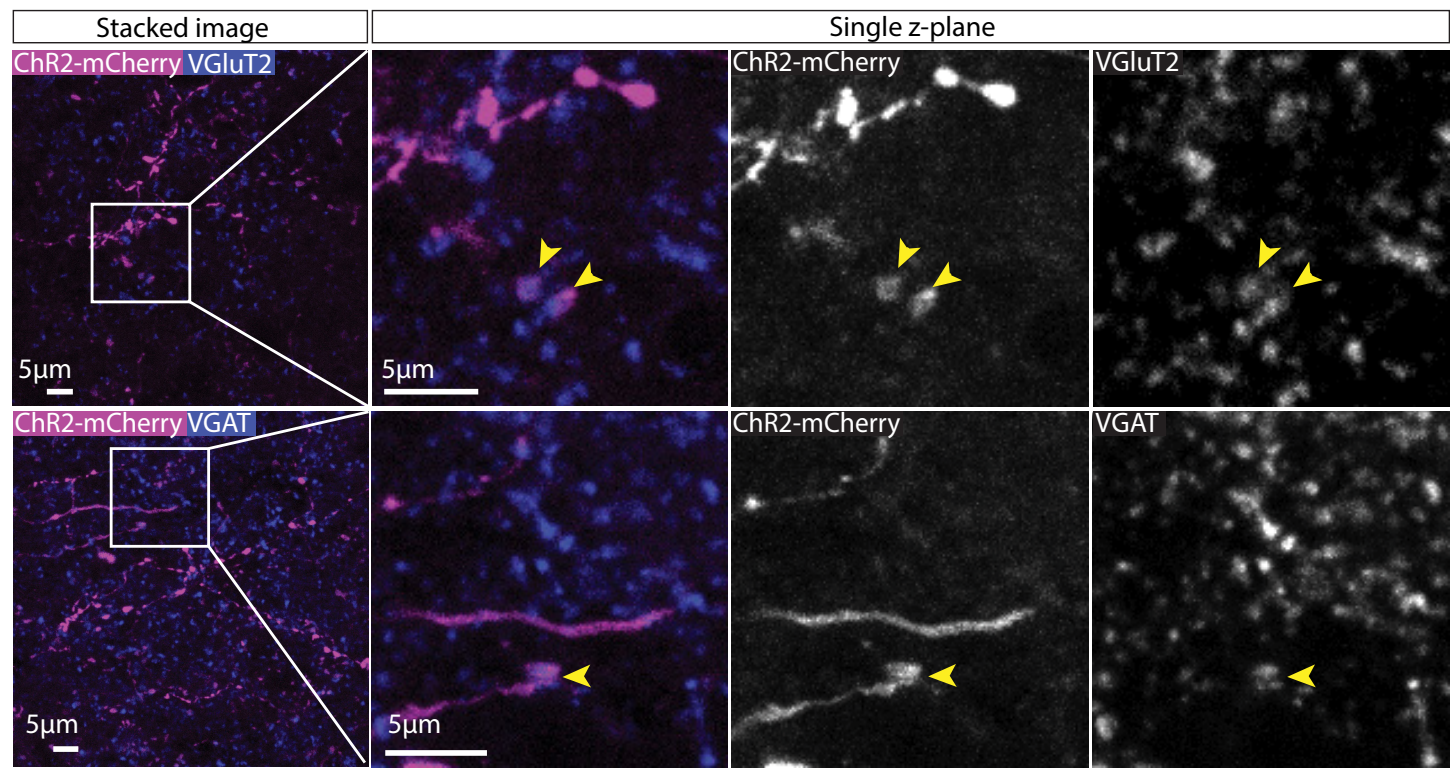

Figure 10. Axonal expression of ChR2-mCherry was colocalized with glutamatergic synaptic boutons in the MnR. A, Representative images of immunolabelling for ChR2-mCherry and 5-HT (which is highly expressed in the MnR compared to nearby regions). Extensive innervation was observed in the MnR with axons often passing in close apposition to 5-HT[1] neurons. $\boldsymbol{B}$, Upper panels show high-magnification representative images of immunolabelling for ChR2-mCherry and VGluT2 in the MnR. Colocalization between ChR2-mCherry and VGluT2 puncta can be seen in single z-plane images, suggesting that these projections are glutamatergic. Lower panels show high-magnification representative images of immunolabelling for ChR2mCherry and VGAT puncta in the MnR. On some occasions, colocalization between ChR2-mCherry and VGAT was observed in single z-plane images, suggesting that some these projections may also be GABAergic. 
neurons in the PBP and SNc. Taken together, it would therefore be surprising if axonal transport of mCherry/ ChR2 was completely absent in one of these populations but not the other.

One intriguing observation was that a subset of nNOS$\mathrm{Cre}+$ neurons in the SNc were $\mathrm{TH}+$. Importantly, these neurons do not send projections outside the SNc. It is, of course, a canonical view of the mesocorticolimbic dopamine system that $\mathrm{TH}+$ neurons in the SNc send extremely dense axonal projections to several target regions, most notably the striatum (Matsuda et al., 2009). Not withstanding the caveats discussed in the previous paragraph, our findings suggest, however, that a subset of $\mathrm{TH}+$ neurons in the SNc are local interneurons (or at least have dramatically more limited axonal projections than typical SNc dopamine neurons). Interestingly, there is evidence for $\mathrm{TH}+$ GABAergic interneurons in the striatum (Dubach et al., 1987; Tashiro et al., 1989; Meredith et al., 1999; O'Byrne et al., 2000; Mao et al., 2001; Petroske et al., 2001; Ibáñez-Sandoval et al., 2010; Unal et al., 2011; Ünal et al., 2015; Xenias et al., 2015). Optogenetic stimulation of these $\mathrm{TH}+$ neurons in the striatum fails to elicit any detectable release of dopamine (Ibáñez-Sandoval et al., 2010; Xenias et al., 2015). In addition, they do not express AADC, dopamine, or DAT (Xenias et al., 2015). Instead, optogentic activation of these neurons elicited GABAmediated IPSCs in mediam spiny neurons (IbáñezSandoval et al., 2010; Xenias et al., 2015). Colocalization with GABA synthesizing enzymes GAD65 and GAD67 has also been reported (Betarbet et al., 1997; Cossette et al., 2005; Mazloom and Smith, 2006; Tandé et al., 2006; San Sebastián et al., 2007). Notably, this interneuron population is considered to be distinct from the nNOS+ interneurons in the striatum (Ibáñez-Sandoval et al., 2010; Tepper et al., 2010). In contrast, we observed coexpression of AADC and DAT in our subset of nonprojecting $\mathrm{TH}+$ neurons in the $\mathrm{SNc}$, suggesting that they may be dopaminergic. It will be important, therefore, to establish whether they release dopamine. Our examination of synaptic terminals in the SNc suggest that some at least may be GABAergic. It is also not clear whether these $\mathrm{TH}+$ interneurons would be mistaken for $\mathrm{TH}+$, long-range projecting dopamine neurons in studies where TH-GFP or $\mathrm{TH}$-Cre mice are used to identify and/or manipulate dopamine neurons.

Glutamate neurons are found sparsely distributed throughout the SNc and VTA, although at a greater density in more medial regions of the VTA (Yamaguchi et al., 2007, 2011, 2013, 2015; Nair-Roberts et al., 2008; Morales and Root, 2014; Root et al., 2016; Morales and Margolis, 2017). Some of these neurons co-release dopamine or GABA (Stuber et al., 2010; Tecuapetla et al., 2010; Root et al., 2014b; Zhang et al., 2015; Yoo et al., 2016). They make local synaptic connections with dopamine and non-dopamine neurons and send projections to several regions including the striatum (Dobi et al., 2010; Hnasko et al., 2012; Root et al., 2014a,b; Taylor et al., 2014). Interestingly, optogenetic excitation of VTA glutamate neurons can have rewarding and aversive effects, depending in part on the site of stimulation, suggesting some functional heterogeneity (Root et al., 2014a; Wang et al., 2015; Qi et al., 2016; Yoo et al., 2016). We have found the nNOS is expressed by glutamate neurons in the VTAR and RLi that send projections most densely to the VP, LH, and MnR. This is consistent with previous reports of non-cell type-specific anterograde labeling of projections from the RLi to the VP, but not NAc (Del-Fava et al., 2007). Based on reports of the full projectome of glutamate neurons in the VTA, which includes extensive projections to regions such as the NAc (Hnasko et al., 2012; Taylor et al., 2014; Qi et al., 2016), we conclude that nNOS+ neurons represent a projection-specific subgroup of this population. As is the case for nNOS+ GABA neurons in the PBP and SNc, because nNOS+ glutamate neurons have a distinct molecular identity understanding their function will be experimentally tractable.

In conclusion, our findings indicate that nNOS is expressed by neurochemically- and anatomically-distinct neuronal sub-groups in a sub-region-specific manner within the VTA and SNc.

\section{References}

Ascoli GA, Alonso-Nanclares L, Anderson SA, Barrionuevo G, Benavides-Piccione R, Burkhalter A, Buzsáki G, Cauli B, Defelipe J, Fairén A, Feldmeyer D, Fishell G, Fregnac Y, Freund TF, Gardner D, Gardner EP, Goldberg JH, Helmstaedter M, Hestrin S, Karube F, et al. (2008) Petilla terminology: nomenclature of features of GABAergic interneurons of the cerebral cortex. Nat Rev Neurosci 9:557-568. CrossRef Medline

Backes E, Hemby SE (2003) Discrete cell gene profiling of ventral tegmental dopamine neurons after acute and chronic cocaine self-administration. J Pharmacol Exp Ther 307:450-459. CrossRef Medline

Betarbet R, Turner R, Chockkan V, DeLong MR, Allers KA, Walters J, Levey Al, Greenamyre JT (1997) Dopaminergic neurons intrinsic to the primate striatum. J Neurosci 17:6761-6768. CrossRef

Brown MT, Tan KR, O'Connor EC, Nikonenko I, Muller D, Lüscher C (2012) Ventral tegmental area GABA projections pause accumbal cholinergic interneurons to enhance associative learning. Nature 492:452-456. CrossRef

Cavalcanti-Kwiatkoski R, Raisman-Vozari R, Ginestet L, Del Bel E (2010) Altered expression of neuronal nitric oxide synthase in weaver mutant mice. Brain Res 1326:40-50. CrossRef Medline

Chieng B, Azriel Y, Mohammadi S, Christie MJ (2011) Distinct cellular properties of identified dopaminergic and GABAergic neurons in the mouse ventral tegmental area. J Physiol 589:3775-3787. CrossRef Medline

Cossette M, Lecomte F, Parent A (2005) Morphology and distribution of dopaminergic neurons intrinsic to the human striatum. $\mathrm{J}$ Chem Neuroanat 29:1-11. CrossRef Medline

Del-Fava F, Hasue RH, Ferreira JG, Shammah-Lagnado SJ (2007) Efferent connections of the rostral linear nucleus of the ventral tegmental area in the rat. Neuroscience 145:1059-1076. CrossRef Medline

Dobi A, Margolis EB, Wang HL, Harvey BK, Morales M (2010) Glutamatergic and nonglutamatergic neurons of the ventral tegmental area establish local synaptic contacts with dopaminergic and nondopaminergic neurons. J Neurosci 30:218-229. CrossRef Medline

Dougalis AG, Matthews GA, Bishop MW, Brischoux F, Kobayashi K, Ungless MA (2012) Functional properties of dopamine neurons and co-expression of vasoactive intestinal polypeptide in the dorsal raphe nucleus and ventro-lateral periaqueductal grey. Eur $\mathrm{J}$ Neurosci 36:3322-3332. CrossRef Medline

Dubach M, Schmidt R, Kunkel D, Bowden DM, Martin R, German DC (1987) Primate neostriatal neurons containing tyrosine hydroxy- 
lase: immunohistochemical evidence. Neurosci Lett 75:205-210. Medline

Franklin KBJ, Paxinos G (2008) The mouse brain in stereotaxic coordinates. Amsterdam, The Netherlands: Academic Press.

Garthwaite J (1991) Glutamate, nitric oxide and cell-cell signalling in the nervous system. Trends Neurosci 14:60-67. Medline

Garthwaite J, Boulton CL (1995) Nitric oxide signaling in the central nervous system. Annu Rev Physiol 57:683-706. CrossRef Medline

Gonzalez-Hernandez T, Rodriguez M (2000) Compartmental organization and chemical profile of dopaminergic and GABAergic neurons in the substantia nigra of the rat. J Comp Neur 421:107-135.

Gotti S, Sica M, Viglietti-Panzica C, Panzica G (2005) Distribution of nitric oxide synthase immunoreactivity in the mouse brain. Microsc Res Tech 68:13-35. CrossRef Medline

Hnasko TS, Hjelmstad GO, Fields HL, Edwards RH (2012) Ventral tegmental area glutamate neurons: electrophysiological properties and projections. J Neurosci 32:15076-15085. CrossRef Medline

Hökfelt T, Rehfeld JF, Skirboll L, Ivemark B, Goldstein M, Markey K (1980) Evidence for coexistence of dopamine and CCK in mesolimbic neurones. Nature 285:476-478. Medline

Huang PL, Dawson TM, Bredt DS, Snyder SH, Fishman MC (1993) Targeted disruption of the neuronal nitric oxide synthase gene. Cell 75:1273-1286. Medline

Ibáñez-Sandoval O, Tecuapetla F, Unal B, Shah F, Koós T, Tepper JM (2010) Electrophysiological and morphological characteristics and synaptic connectivity of tyrosine hydroxylase-expressing neurons in adult mouse striatum. J Neurosci 30:6999-7016. CrossRef Medline

Isaacs KR, Jacobowitz DM (1994) Mapping of the colocalization of calretinin and tyrosine hydroxylase in the rat substantia nigra and ventral tegmental area. Exp Brain Res 99:34-42. Medline

Klausberger T, Somogyi P (2008) Neuronal diversity and temporal dynamics: the unity of hippocampal circuit operations. Science 321:53-57. CrossRef Medline

Klejbor I, Domaradzka-Pytel B, Ludkiewicz B, Wójcik S, Moryś J (2004) The relationships between neurons containing dopamine and nitric oxide synthase in the ventral tegmental area. Folia Histochem Cytobiol 42:83-87. Medline

Klink R, de Kerchove d'Exaerde A, Zoli M, Changeux JP (2001) Molecular and physiological diversity of nicotinic acetylcholine receptors in the midbrain dopaminergic nuclei. J Neurosci 21: 1452-1463. Medline

Klugmann M, Symes CW, Leichtlein CB, Klaussner BK, Dunning J, Fong D, Young D, During MJ (2005) AAV-mediated hippocampal expression of short and long Homer 1 proteins differentially affect cognition and seizure activity in adult rats. Mol Cell Neurosci 28:347-360. CrossRef

Knowles RG, Palacios M, Palmer RM, Moncada S (1989) Formation of nitric oxide from L-arginine in the central nervous system: a transduction mechanism for stimulation of the soluble guanylate cyclase. Proc Natl Acad Sci USA 86:5159-5162. Medline

Lein ES, Hawrylycz MJ, Ao N, Ayres M, Bensinger A, Bernard A, Boe AF, Boguski MS, Brockway KS, Byrnes EJ, Chen L, Chen L, Chen TM, Chin MC, Chong J, Crook BE, Czaplinska A, Dang CN, Datta S, Dee NR, et al. (2007) Genome-wide atlas of gene expression in the adult mouse brain. Nature 445:168-176. CrossRef Medline

Liang CL, Sinton CM, German DC (1996) Midbrain dopaminergic neurons in the mouse: co-localization with calbindin-D28k and calretinin. Neuroscience 75:523-533. Medline

Mao L, Lau YS, Petroske E, Wang JQ (2001) Profound astrogenesis in the striatum of adult mice following nigrostriatal dopaminergic lesion by repeated MPTP administration. Brain Res Dev Brain Res 131:57-65. Medline

Margolis EB, Toy B, Himmels P, Morales M, Fields HL (2012) Identification of rat ventral tegmental area GABAergic neurons. PLoS One 7:e42365. CrossRef Medline

Matsuda W, Furuta T, Nakamura KC, Hioki H, Fujiyama F, Arai R, Kaneko T (2009) Single nigrostriatal dopaminergic neurons form widely spread and highly dense axonal arborizations in the neostriatum. J Neurosci 29:444-453. CrossRef Medline
Mazloom M, Smith Y (2006) Synaptic microcircuitry of tyrosine hydroxylase-containing neurons and terminals in the striatum of 1-methyl-4-phenyl-1,2,3,6-tetrahydropyridine-treated monkeys. J Comp Neur 495:453-469. CrossRef Medline

Meredith GE, Farrell T, Kellaghan P, Tan Y, Zahm DS, Totterdell S (1999) Immunocytochemical characterization of catecholaminergic neurons in the rat striatum following dopamine-depleting lesions. Eur J Neurosci 11:3585-3596. Medline

Merrill CB, Friend LN, Newton ST, Hopkins ZH, Edwards JG (2015) Ventral tegmental area dopamine and GABA neurons: physiological properties and expression of mRNA for endocannabinoid biosynthetic elements. Sci Rep 5:16176. CrossRef Medline

Morales M, Root DH (2014) Glutamate neurons within the midbrain dopamine regions. Neuroscience 282:60-68. CrossRef Medline

Morales M, Margolis EB (2017) Ventral tegmental area: cellular heterogeneity, connectivity and behaviour. Nat Rev Neurosci 18:7385. CrossRef Medline

Mitkovski M, Padovan-Neto FE, Raisman-Vozari R, Ginestet L, daSilva CA, Del-Bel EA (2012) Investigations into potential extrasynaptic communication between the dopaminergic and nitrergic systems. Front Physiol 3:372. CrossRef Medline

Nair-Roberts RG, Chatelain-Badie SD, Benson E, White-Cooper H, Bolam JP, Ungless MA (2008) Stereological estimates of dopaminergic, GABAergic and glutamatergic neurons in the ventral tegmental area, substantia nigra and retrorubral field in the rat. Neuroscience 152:1024-1031. CrossRef Medline

O'Byrne MB, Bolam JP, Hanley JJ, Tipton KF (2000) Tyrosinehydroxylase immunoreactive cells in the rat striatum following treatment with MPP+. Adv Exp Med Biol 483:369-374.

Olson VG, Nestler EJ (2007) Topographical organization of GABAergic neurons within the ventral tegmental area of the rat. Synapse 61:87-95. CrossRef Medline

Omelchenko N, Sesack SR (2009) Ultrastructural analysis of local collaterals of rat ventral tegmental area neurons: GABA phenotype and synapses onto dopamine and GABA cells. Synapse 63:895906. CrossRef Medline

Petroske E, Meredith GE, Callen S, Totterdell S, Lau YS (2001) Mouse model of Parkinsonism: a comparison between subacute MPTP and chronic MPTP/probenecid treatment. Neuroscience 106:589-601. Medline

Qi J, Zhang S, Wang HL, Barker DJ, Miranda-Barrientos J, Morales M (2016) VTA glutamatergic inputs to nucleus accumbens drive aversion by acting on GABAergic interneurons. Nat Neurosci 19: 725-733. CrossRef

Rodrigo J, Springall DR, Uttenthal O, Bentura ML, Abadia-Molina F, Riveros-Moreno V, Martínez-Murillo R, Polak JM, Moncada S (1994) Localization of nitric oxide synthase in the adult rat brain. Philos Trans R Soc Lond B Biol Sci 345:175-221. CrossRef

Rogers JH (1992) Immunohistochemical markers in rat brain: colocalization of calretinin and calbindin-D28k with tyrosine hydroxylase. Brain Res 587:203-210. Medline

Root DH, Mejias-Aponte CA, Qi J, Morales M (2014a) Role of glutamatergic projections from ventral tegmental area to lateral habenula in aversive conditioning. J Neurosci 34:13906-13910. CrossRef

Root DH, Mejias-Aponte CA, Zhang S, Wang HL, Hoffman AF, Lupica CR, Morales M (2014b) Single rodent mesohabenular axons release glutamate and GABA. Nat Neurosci 17:1543-1551. CrossRef

Root DH, Wang HL, Liu B, Barker DJ, Mód L, Szocsics P, Silva AC, Maglóczky Z, Morales M (2016) Glutamate neurons are intermixed with midbrain dopamine neurons in nonhuman primates and humans. Sci Rep 6:30615. CrossRef Medline

San Sebastián W, Guillén J, Manrique M, Belzunegui S, Ciordia E, Izal-Azcárate A, Garrido-Gil P, Vázquez-Claverie M, Luquin MR (2007) Modification of the number and phenotype of striatal dopaminergic cells by carotid body graft. Brain 130:1306-1316. CrossRef Medline

Sandhu EC, Fernando ABP, Irvine EE, Tossell K, Kokkinou M, Glegola J, Smith MA, Howes OD, Withers DJ, Ungless MA (2018) 
Phasic stimulation of midbrain dopamine neuron activity reduces salt consumption. eNeuro 5. CrossRef

Sanz E, Yang L, Su T, Morris DR, McKnight GS, Amieux PS (2009) Cell-type-specific isolation of ribosome-associated mRNA from complex tissues. Proc Natl Acad Sci USA 106:13939-13944. CrossRef Medline

Seroogy K, Ceccatelli S, Schalling M, Ho"Kfelt T, Frey P, Walsh J, Dockray G, Brown J, Buchan A, Goldstein M (1988) A subpopulation of dopaminergic neurons in rat ventral mesencephalon contains both neurotensin and cholecystokinin. Brain Res 455:88-98. CrossRef

Seroogy K, Schalling M, Brené S, Dagerlind Å, Chai SY, Hökfelt T, Persson H, Brownstein M, Huan R, Dixon J, Filer D, Schlessinger D, Goldstein M (1989) Cholecystokinin and tyrosine hydroxylase messenger RNAs in neurons of rat mesencephalon: peptide/ monoamine coexistence studies using in situ hybridization combined with immunocytochemistry. Exp Brain Res 74:149-162.

Stuber GD, Hnasko TS, Britt JP, Edwards RH, Bonci A (2010) Dopaminergic terminals in the nucleus accumbens but not the dorsal striatum corelease glutamate. J Neurosci 30:8229-8233. CrossRef

Tan KR, Yvon C, Turiault M, Mirzabekov JJ, Doehner J, Labouèbe G, Deisseroth K, Tye KM, Lüscher C (2012) GABA neurons of the VTA drive conditioned place aversion. Neuron 73:1173-1183. CrossRef Medline

Tandé D, Höglinger G, Debeir T, Freundlieb N, Hirsch EC, François C (2006) New striatal dopamine neurons in MPTP-treated macaques result from a phenotypic shift and not neurogenesis. Brain 129: 1194-1200. CrossRef

Tashiro Y, Sugimoto T, Hattori T, Uemura Y, Nagatsu I, Kikuchi H, Mizuno N (1989) Tyrosine hydroxylase-like immunoreactive neurons in the striatum of the rat. Neurosci Lett 97:6-10. Medline

Taylor SR, Badurek S, Dileone RJ, Nashmi R, Minichiello L, Picciotto MR (2014) GABAergic and glutamatergic efferents of the mouse ventral tegmental area. J Comp Neur 522:3308-3334. CrossRef Medline

Tecuapetla F, Patel JC, Xenias H, English D, Tadros I, Shah F, Berlin J, Deisseroth K, Rice ME, Tepper JM, Koos T (2010) Glutamatergic signaling by mesolimbic dopamine neurons in the nucleus accumbens. J Neurosci 30:7105-7110. CrossRef Medline

Tepper JM, Tecuapetla F, Koos T, Ibanez-Sandoval O (2010) Heterogeneity and diversity of striatal GABAergic interneurons. Front Neuroanat 4:150.

Unal B, Ibáñez-Sandoval O, Shah F, Abercrombie ED, Tepper JM (2011) Distribution of tyrosine hydroxylase-expressing interneurons with respect to anatomical organization of the neostriatum. Front Syst Neurosci 5:41. CrossRef Medline

Ünal B, Shah F, Kothari J, Tepper JM (2015) Anatomical and electrophysiological changes in striatal $\mathrm{TH}$ interneurons after loss of the nigrostriatal dopaminergic pathway. Brain Struct Funct 220: 331-349. CrossRef Medline

van Zessen R, Phillips JL, Budygin EA, Stuber GD (2012) Activation of VTA GABA neurons disrupts reward consumption. Neuron 73: 1184-1194. CrossRef Medline

Vincent SR, Kimura H (1992) Histochemical mapping of nitric oxide synthase in the rat brain. Neuroscience 46:755-784. Medline

Viskaitis P, Irvine EE, Smith MA, Choudhury Al, Alvarez-Curto E, Glegola JA, Hardy DG, Pedroni SMA, Paiva Pessoa MR, Fernando ABP, Katsouri L, Sardini A, Ungless MA, Milligan G, Withers DJ (2017) Modulation of SF1 neuron activity coordinately regulates both feeding behavior and associated emotional states. Cell Rep 21:3559-3572. CrossRef Medline

Vong L, Ye C, Yang Z, Choi B, Chua S Jr, Lowell BB (2011) Leptin action on GABAergic neurons prevents obesity and reduces inhibitory tone to POMC neurons. Neuron 71:142-154. CrossRef

Wang HL, Qi J, Zhang S, Wang H, Morales M (2015) Rewarding effects of optical stimulation of ventral tegmental area glutamatergic neurons. J Neurosci 35:15948-15954. CrossRef Medline

Wang Y, Marsden PA (1995) Nitric oxide synthases: gene structure and regulation. Adv Pharmacol 34:71-90. Medline

Xenias HS, Ibáñez-Sandoval O, Koós T, Tepper JM (2015) Are striatal tyrosine hydroxylase interneurons dopaminergic? J Neurosci 35: 6584-6599. CrossRef Medline

Yamaguchi T, Sheen W, Morales M (2007) Glutamatergic neurons are present in the rat ventral tegmental area. Eur $\mathrm{J}$ Neurosci 25:106-118. CrossRef Medline

Yamaguchi T, Wang HL, Li X, Ng TH, Morales M (2011) Mesocorticolimbic glutamatergic pathway. J Neurosci 31:8476-8490. CrossRef Medline

Yamaguchi T, Wang HL, Morales M (2013) Glutamate neurons in the substantia nigra compacta and retrorubral field. Eur J Neurosci 38:3602-3610. CrossRef Medline

Yamaguchi T, Qi J, Wang HL, Zhang S, Morales M (2015) Glutamatergic and dopaminergic neurons in the mouse ventral tegmental area. Eur J Neurosci 41:760-772. CrossRef Medline

Yoo JH, Zell V, Gutierrez-Reed N, Wu J, Ressler R, Shenasa MA, Johnson AB, Fife KH, Faget L, Hnasko TS (2016) Ventral tegmental area glutamate neurons co-release GABA and promote positive reinforcement. Nat Commun 7:13697. CrossRef Medline

Yu X, Ye Z, Houston CM, Zecharia AY, Ma Y, Zhang Z, Uygun DS, Parker S, Vyssotski AL, Yustos R, Franks NP, Brickley SG, Wisden W (2015) Wakefulness is governed by GABA and histamine cotransmission. Neuron 87:164-178. CrossRef Medline

Zhang S, Qi J, Li X, Wang HL, Britt JP, Hoffman AF, Bonci A, Lupica CR, Morales M (2015) Dopaminergic and glutamatergic microdomains in a subset of rodent mesoaccumbens axons. Nat Neurosci 18:386-392. CrossRef 